\title{
Una reescritura aristocrática de la Estoria de España. La Crónica abreviada de don Juan Manuel ${ }^{1}$
}

\author{
An Aristocratic Rewriting of the Estoria de España, Juan Manuel's Crónica \\ abreviada
}

(i) Mario Cossío Olavide

mario.cossio@uah.es

Universidad de Alcalá, España

Recepción: 23 Abril 2021

Aprobación: 02 Agosto 2021

Publicación: 01 Noviembre 2021

Cita sugerida: Cossío Olavide, M. (2021). Una reescritura aristocrática de la Estoria de España. La Crónica abreviada de don Juan Manuel. Olivar, 21(34), e105. https://doi.org/10.24215/18524478e105

\begin{abstract}
Resumen: La crítica concibe habitualmente la Crónica abreviada de Juan Manuel como un resumen o un índice de la Estoria de España, esto a pesar de que su contenido indique que es una reacción al pensamiento de Alfonso X. En este artículo estudio cuáles son los efectos de la abbreviatio de la crónica sobre los eventos narrados por la historiografía alfonsí y postalfonsí. Mi propósito es demostrar que la reescritura de la "estoria" implica una reorientación del discurso historiográfico; con ello, Juan Manuel enfatiza la corrupción moral de los reyes, convierte a la aristocracia en una fuerza de control político y rescata figuras heroicas de la nobleza como modelos para su ética señorial.

Palabras clave: Juan Manuel, Crónica abreviada, Estoria de España, Historiografía medieval, Alfonso X.

Abstract: Although scholars often consider Juan Manuel's Crónica abreviada to be a mere summary or index of the Estoria de España, its contents suggest that it can be better characterized as a reaction to Alfonso X's ideology. In this article, I study the effect of the chronicle's abbreviatio on the narration of events taken from Alfonsine and post-Alfonsine historiography. My purpose is to show that this rewriting of "history" reorients the historiographical discourse to emphasize the moral decadence of kings, transform the nobility into a force of political control, and posit heroic figures of the aristocracy as models of a new seigneurial ethics.
\end{abstract}

Keywords: Juan Manuel, Crónica abreviada, Estoria de España, Medieval historiography, Alfonso X.

La Crónica abreviada, el texto historiográfico que inaugura la producción intelectual de Juan Manuel, adelanta ideas que el prosista desarrollará en sus siguientes obras de educación cortesana y que forman el núcleo de su ideario político y estético: la necesidad de una sólida educación nobiliaria, la importancia de defender los derechos de la aristocracia y la utilidad de la escritura como un mecanismo de reacción frente a la ideología regalista. Que Juan Manuel haya elegido un libro de historia para plasmar estos fundamentos es una herencia clara de la clerecía cortesana alfonsí, donde la historia permite "aportar racionalidad al ejercicio del poder" (Funes, 1997,p. 9). 
Profundizando los planteamientos de Gómez Redondo (1998) sobre Juan Manuel, en otros trabajos he sostenido que los tratados didácticos del prosista castellano se alejan de los sistemas culturales de la clerecía cortesana y la clerecía aristocrática molinista, especialmente en lo que refiere a la creación de modelos regios y consiliares y en la configuración de las relaciones sociales dentro del mundo cortesano (Cossío Olavide, 2019a, 2019b y 2022b). Discrepando con lo sostenido por Catalán (1977/1992) y Orduna (1979/2011) sobre el reverente tratamiento de la materia alfonsí en las primeras obras de Juan Manuel, propongo que ya desde el inicio de su producción prosística, el escritor reacciona y reconfigura este modelo literario. Su crónica, por tanto, debe ser entendida como una meditada manipulación de la tradición historiográfica alfonsí y postalfonsí. Nacida en un espacio excéntrico al poder monárquico, el principal propósito de la Crónica abreviada es ser un espejo moralizador para la nobleza castellana del siglo XIV.

\section{LA CRÓNICA ABREVIADA Y LA HISTORIOGRAFÍA POSTALFONSÍ}

Juan Manuel debió entender que las empresas historiográficas de Alfonso X, la Estoria de España $(=E E)$ y la General estoria $(=G E)$, codificaban el pasado de la Península y lo integraban al presente, proponiendo un devenir histórico providencialista, un discurso profético que alcanzaba su plenitud en los tiempos del Rey Sabio (Gingras, 1990; Gómez Redondo, 1998; Mencé-Caster, 2011). Él mismo intentaría algo similar hacia 1345 en el Libro de las tres razones.

Tras la muerte de Alfonso X, y al desmontarse los mecanismos articuladores de su entramado cortesano, Castilla no tuvo un proyecto historiográfico de magnitud comparable hasta bien avanzado el reinado de Alfonso XI. Esto cambió alrededor de la batalla del Salado (1340), cuando el rey ordenó la revisión de los libros de historia de su cámara y encargó la escritura de cuatro crónicas regias, que narraban los eventos desde el reinado de Alfonso X hasta el suyo, completando así el hiato de la historia castellana reciente. ${ }^{2}$

A pesar de la falta de un impulso historiográfico supervisado directamente por la corona, entre 1284 y 1340 existieron esfuerzos aislados nacidos fuera de los espacios curiales. En líneas generales, estas empresas servían dos propósitos: completar el relato inconcluso de la $E E$ de Alfonso $\mathrm{X}$-que llega hasta el reino de Fernando II de León-y revisar su contenido ideológico, adaptándolo a nuevas condiciones políticas y culturales (Gómez Redondo, 2000). Durante el reinado de Sancho IV, en el entorno catedralicio de Toledo se produce una Versión retóricamente amplificada de la EE. En ella se completan secciones del texto alfonsí conservadas en borradores y cuadernos de trabajo. El arcediano de Toledo Jofré de Loaysa, figura cercana al cardenal García Gudiel, escribe en los primeros años del siglo XIV la Crónica de los reyes de Castilla, que actualiza la historia de Ximénez de Rada hasta 1304. En los últimos años del reinado de Fernando IV, se redacta la Crónica particular de San Fernando (=CPSF), que se empalma con otros materiales postalfonsíes para completar la $E E$ hasta la muerte de Fernando III.

Tanto en la CPSF, como en otras redacciones postalfonsíes, como la Crónica manuelina $(=C M)$, modelo de la crónica de Juan Manuel, Funes (2015) nota alteraciones del relato alfonsí que ofrecen una visión más positiva de la nobleza. La aparición de estas redacciones es un fenómeno que Hijano Villegas (2006) considera un "giro copernicano" en la escritura de la historia; son indicativas, además, de los turbulentos eventos políticos que afectan la corona desde finales del siglo XIII. Se trata de un periodo marcado por la Conjura de Lerma en 1272 y la revuelta nobiliaria que desposee a Alfonso X en 1282, eventos seguidos por varios levantamientos contra Sancho IV y su temprana muerte en 1295. A partir de este momento, la crisis de la monarquía castellana se instala permanentemente hasta 1325. Son años en los que la nobleza ocupa un rol mucho más activo en el gobierno e impone, a menudo por la fuerza, su voluntad.

Aunque el origen de las crónicas postalfonsíes es aún materia de discusión, Funes (2003, 2008 y 2015) e Hijano Villegas (2006) especulan que su contenido y su orientación nobiliaria pueden ser prueba de que su génesis estuvo relacionada con las cancillerías señoriales, empoderadas durante los años de virtual interregno entre los reinados de Sancho IV y Alfonso XI. No es descabellado sospechar que nacieran bajo el auspicio 
de miembros de algunos importantes linajes, como los Castro, los Díaz de Haro o los Lara, o los infantes de Castilla, quienes ocuparon cargos en los consejos regios y en los comités de tutoría de Fernando IV y Alfonso XI. Esta situación, además, les pudo ofrecer acceso a la cámara regia que guardaba los cuadernos alfonsíes (Montoya Martínez, 2002). Por oposición a este incierto origen, la particularidad de la Crónica abreviada es que es la primera obra historiográfica del siglo XIV que se puede localizar en una cancillería nobiliaria, situándola en un contexto intelectual y político preciso.

Tras forzar su reconocimiento como integrante del segundo comité de tutoría de Alfonso XI en 1319, Juan Manuel ordenó la composición de la Crónica abreviada, obra que recurre a la abbreviatio para alterar y enmendar el sentido del texto que él consideraba era la $E E$ de Alfonso X. El resultado de la selección y la abreviación es una obra afín al espíritu de las otras historias nobiliarias postalfonsíes. Catalán (1977/1992) sostiene que la crónica reinterpreta el texto alfonsí y construye, en la medida que el material original lo permite, un "punto de vista aristocrático" de la historia peninsular (p. 226). Tal direccionamiento indica la temprana búsqueda, por parte del autor, de nuevas formas de pensar el rol de la nobleza en la sociedad castellana. Juan Manuel sigue así las ideas de otros anónimos cronistas postalfonsíes, para quienes escribir la historia requiere forzosamente revisar y corregir los errores de los historiadores del pasado. Así ocurre en la Estoria cabadelante que forma parte de la CPSF:

Manera de los estoriadores e de todos cuantos començadores de razones e de grandes fechos estorialmente quisieron departir, de emendar siempre en las razones pasadas (que fallaron d'aquellos que ante que ellos dixeron, si les vino a punto de fablar en aquella misma razón) alguna mengua e de escatimar ý e complir lo que en las dichas razones menguado fue. ( $E 2$, fol. $333 \mathrm{rb}$ )

Aunque es un lugar común citar el prólogo de la Crónica abreviada como un ejemplo de la admiración e inspiración alfonsí de Juan Manuel (Orduna, 1970/2011; Catalán, 1977/1992), creo que es necesario revaluar esta percepción. Detrás de sus homenajes hay una latente urgencia, un discurso que plantea la necesidad de "emendar" la historia de Alfonso X y producir una obra que se ajuste a los nuevos tiempos.

\section{El prólogo de la CRónica abreviada}

La Crónica abreviada fue escrita en el periodo que va desde la inclusión de Juan Manuel en el comité de tutoría de Alfonso XI, tras la muerte de sus primeros tutores en el desastre de la Vega de Granada, en junio de 1319, y la declaración de mayoridad del rey y la disolución del comité, en agosto de 1325. El prólogo se refiere a él como "don Joán, fijo del muy noble infante don Manuel, tutor del muy alto e muy noble señor rey don Alfonso su sobrino, e guarda de los sus regnos" (2007, p. 65). ${ }^{3}$ El “fecho de la tutoría” permite contextualizar y comprender el propósito de la crónica. Juan Manuel inicialmente usurpa la función de tutor, atribuyéndose la potestad de administrar justicia y recaudar impuestos en nombre del infante rey. Al hacerlo, también limita su poder, gesto que cuenta con la aprobación de miembros de importantes linajes de la aristocracia castellana. En un plano literario, esta acción es acompañada por otra usurpación de una tarea regia en el mundo alfonsí: escribir la historia del reino. ${ }^{4}$

Juan Manuel cree, dice el prólogo, que su crónica refleja fielmente la $E E$ y, por tanto, el pensamiento y la voluntad creadora del Rey Sabio:

\footnotetext{
E por ende el muy noble rey don Alfonso (...) porque los grandes fechos que pasaron, señaladamente lo que pertenece a la estoria d'España, fuesen sabidos e non cayesen en olvido, fizo ayuntar los que falló que cumplían para los contar (...) Porque don Joán su sobrino se pagó mucho d'esta su obra e por la saber mejor (...) fizo poner en este libro en pocas razones todos los grandes fechos que se ý contienen. (2007, pp. 67-68)
}

Esta afirmación permite plantear que Juan Manuel veía la $E E$ como un proyecto unitario, que él conocía a través de un testimonio específico, la $C M$, redacción postalfonsí realizada entre 1295 y $1320 .^{5}$ Funes (2019) explica que, aunque nosotros seguimos descifrando el enmarañado conjunto de redacciones y capas de 
sobrescritura de la historiografía alfonsí y postalfonsí, "los usuarios medievales solo veían un relato histórico continuado del pasado de España, sin mayor conciencia del carácter fragmentario y heterogéneo de la historia narrada" (p. 209). ${ }^{6}$

Desgraciadamente, la importancia de la Crónica abreviada es injustamente menguada al considerársele una mera abreviación, resumen o índice de la EE (Menéndez Pidal, 1955; Orduna, 1970/2011; Dyer, 1990; Fernández-Ordóñez, 1992 y 2000b; Bautista Crespo, 2000; Hijano Villegas, 2011 y 2016; Bautista 2014). Insistiendo en la ineludible gravedad del modelo alfonsí, Hijano Villegas (2014) advierte que cualquier aproximación a la crónica debe aceptar que carece de sentido "escudriñar el texto (...) en busca de desviaciones con respecto al de la Crónica manuelina, con vistas a reconstruir el sesgo ideológico que anima la selección o el tratamiento del material alfonsí" (p. 81). Considero que esta lectura contradice una realidad discursiva que confirma una voluntad editorial que convierte los largos capítulos del original en precisas viñetas cuyos contenidos son fácilmente asibles y comprensibles para los lectores medievales. Además, la crónica transmite una particular visión de los lazos entre la aristocracia y los reyes que refleja, y de cierto modo prefigura, las formas que Juan Manuel empleó para relacionarse con el poder durante su vida. Finalmente, no puede negarse que cualquier labor de abreviación y reescritura, independientemente de su contexto histórico específico, siempre responde a una visión del mundo distinta que el original del que se parte. ${ }^{7}$ Aunque Sontag (1966) escribe sobre la interpretación y no la abreviación, sus palabras son igualmente útiles para comprender la distancia conceptual entre ambas historias:

Interpretation thus presupposes a discrepancy between the clear meaning of the text and the demands of (later) readers. It seeks to resolve that discrepancy. The situation is that for some reason a text has become unacceptable; yet it cannot be discarded. Interpretation is a radical strategy for conserving an old text, which is thought too precious to repudiate, by revamping it. The interpreter, without actually erasing or rewriting the text, is altering it. But he can't admit to doing this. He claims to be only making it intelligible, by disclosing its true meaning. However far the interpreters alter the text (...) they must claim to be reading off a sense that is already there. (p. 6)

Hathaway (1989) explica que esto es lo que hacen los compilatores escolásticos, reacomodando una vieja tradición textual a nuevos escenarios hermenéuticos, "because that material is useful or instructive in the context of its new presentation" (p. 42). Así, se innova, pero se mantiene la apariencia de continuidad, como Guenée (1985) observa: "la compilation [de l'histoire] n'est pas simplement répétition, elle est recréation" (p. 126). ${ }^{8}$ Catalán (1969) advierte que esto ya ocurre en las historias alfonsíes: "al tratar de ofrecer al lector una versión completa, razonada y palpable de lo que las fuentes decían, los estoriadores alfonsíes actualizan y deforman el sentido de esas fuentes, y, naturalmente, cambian por completo el estilo de los originales" (p. 423). Esto también sucede en la crónica, cuyo prólogo sostiene que Juan Manuel se propone hacer más comprensible (make intelligible) una obra demasiado compleja para los lectores del siglo XIV, pues "el su entendimiento non abondava a retener todas las estorias que son en las dichas Crónicas [del rey don Alfonso]" (2007, p. 68). Por ello,

sacó de la su obra complida una obra menor e non la fizo sinon para sí en que leyese, e cuando alguna razón e palabra ý fallare que non sea tan apuesta nin tan complida como era menester non ha por qué poner la culpa a otri sinon a sí mismo. (2007, p. 68)

Estas palabras justifican la labor cronística de Juan Manuel y son un "gesto enunciativo primordial” (Funes, 2000, p. 783), con el que el autor asume la responsabilidad de su escritura. Con ellas, también alega la necesidad de desarrollar un nuevo modelo prosístico, capaz de responder a lo que percibe como cierto decaimiento cultural, ilustrado por la mengua del entendimiento de los nobles castellanos como él, tema sobre el que vuelve en el prólogo del Libro de la caza. Aquí también se avanza una primera reacción al estilo de la historiografía alfonsí: "E este muy noble rey don Alfonso (...) ordenó muy complidamente la Crónica de España e púsolo todo complido e por muy apuestas razones e en las menos palabras que se podía poner" (2007, p. 67). ${ }^{9}$ 
Juan Manuel describe la EE como una obra "complida", perfecta pero también extensa y desarrollada. Este rasgo resulta del ambicioso plan alfonsí, narrar toda la historia peninsular desde el diluvio hasta el presente del rey, y su forma de composición, mediante la traducción, selección, reacomodo y amplificación de obras historiográficas anteriores (Fernández-Ordóñez, 1992). Aunque la excusatio de incapacidad autorial es parte habitual de la humilitas de los prólogos medievales, desde el siglo XIII asimilada en las crónicas, creo que en este caso no responde a un modelo retórico; antes, es una reflexión sobre el quehacer de la escritura de un autor que se siente poco preparado para competir con la capacidad de trabajo de los talleres alfonsíes y su parafernalia lingüística. Reflexionando sobre los preceptos estilísticos que rigen la escritura de la historia, Juan Manuel propone un nuevo ideal: el de la prosa "menor", que sigue aspirando a ser "complida", pero nunca es oscura ni breve. Es, más bien, "declarada”, según una teoría que desarrolla en el Libro de los estados (1991, p. 194). No se trata, pues, de una escritura "de razones nin por palabras tan sotiles que los que las oyeren non las entiendan o por que tomen dubda en lo que oyen" (2007, p. 65).

Además de estas innovaciones en materia de estilo, el prólogo de la crónica también abandona la estructura de su modelo. Siguiendo el inicio de De rebus Hispaniae, el prólogo de la EE comienza:

Los sabios antigos que fueron en los tiempos primeros e fallaron los saberes e las otras cosas tovieron que menguarién en sus fechos e en su lealtad si tan bien no lo quisiessen pora los que avién de venir como pora sí mismos o pora los otros que eran en so tiempo. E entendiendo por los fechos de Dios, que son espiritales, que los saberes se perderién muriendo aquellos que lo sabién e non dexando remembrança, porque no cayessen en olvido mostraron manera por que lo sopiessen los que avién de venir empós ellos. E por buen entendimiento conocieron las cosas que eran estonces e buscando e escodriñando con grand estudio sopieron las que avién de venir. (E1, fol. 2ra)

La labor compilatoria de los sabios del pasado se debe a su lealtad hacia los hombres del futuro, valor clave en la clerecía cortesana (Gómez Redondo, 1998). Su conexión con el presente se establece gracias a una profunda investigación que les permite dar con conocimientos ocultos. Tal acto premonitorio enlaza la labor del taller historiográfico alfonsí con la de los talleres científicos, que trabajaban paralelamente en traducciones de tratados árabes y hebreos de astrología y magia (Fernández Fernández, 2013). ${ }^{10}$ La profecía establece un puente entre el conocimiento del pasado y la plenitud del presente del rey, quien recupera este saber antiguo y lo emplea para restituir el señorío de España (Funes, 1997; Ward, 2012).

El prólogo de la crónica reestructura esta materia. El texto comienza con una introducción que explica el orden de la creación, preocupación escolástica que el autor desarrolla en el Libro del cavallero e del escudero y el Libro de los estados. Aunque la primera impresión puede ser que Juan Manuel altera su modelo para construir su autoridad enunciativa como historiador, hay varias diferencias que develan una tensa relación con este:

Comoquier que entre Dios e los omnes á muy pequeña comparación, como puede ser entre criador e criatura, pero porque tovo Nuestro Señor Dios por bien qu'el omne fuese fecho a su semejança e esta semejança es la razón e el saber e el libre alvedrío que Dios puso en el omne, e porque los omnes son cosa fallecedera muy aína, tan bien en la vida como en el saber (...) tovieron por bien los sabios antiguos de fazer libros en que posieron los saberes e las remembranças de las cosas que pasaron, tan bien de las leyes que an los omnes para salvar las ánimas, a que llaman Testamento Viejo e Testamento Nuevo, como de los ordenamientos e posturas que fizieron los papas e los emperadores e reyes, a que llaman Decreto e Decretales e leyes e fueros, como de los saberes, a que llaman ciencias e artes, como de los grandes fechos e cosas que pasaron, a que llaman crónicas. (2007, pp. 66-67)

Por oposición a los astrólogos alfonsíes, los sabios de Juan Manuel actúan en campos del conocimiento muy bien definidos y de corte escolástico: las leyes espirituales eternas (la Biblia), el derecho canónico (el Decretum de Graciano y los Decretales de Gregorio IX), las leyes y fueros del comportamiento humano y las ciencias y artes universitarias (trivium y quadrivium, logica nova). Por ningún lado se alude a la lealtad de estos sabios ni se sostiene que sus estudios son el resultado de un acto profético. Siguiendo una concepción aristotélicotomista, el prólogo propone que el orden humano es una reflexión del orden divino y que, además, puede encerrarse y estudiarse en categorías específicas, una de ellas la historia. ${ }^{11}$ Este discurso muestra un cambio de percepción sobre la utilidad de la historiografía, que aquí es un medio para transmitir un proyecto didáctico 
nobiliario. Algo análogo sucede en otra refundición alfonsí, la Crónica geral de Espanha de 1344 del conde de Barcelos, cuyas primeras líneas acusan una reorientación similar: ${ }^{12}$

Os mui nobres barões e de grande entendimiento, que escreverom as estorias antigas das cavalarias e dos outros nobres feitos e acharom os saberes e as outras façanhas per que os homées podem aprender os boos costumes e saber os famosos feitos que fezerom os antigos, teverom que minguariam muito em seus boos feitos e em sua bondade e lealdade se o assi nom quisiessem fazer pera os que aviam de vïir depois como pera si mesmos e pera os outros que eran em seus tempos. (Cintra, 1951-1965, Vol. 2, p. 3)

Pedro Afonso también articula sus ideas desde una óptica señorial, trocando los sabios de la antigüedad por nobles. Para él, la escritura de la historia se convierte en la tarea de los aristócratas y no la de los reyes, como propone el prólogo alfonsí. Este cambio explica la introducción de nuevas referencias al prólogo, como los combates y los hechos de armas, que aluden a eventos dominados por los hidalgos. El propósito de tales historias y hazañas es educar en la moral caballeresca a la nobleza del presente. ${ }^{13}$

Ambas crónicas dejan de lado el elemento profético al que recurren los historiadores alfonsíes. En ellas, el conocimiento del pasado es el producto del entendimiento humano, libre de obligaciones de vasallaje, que se manifiesta en leyes que rigen el mundo espiritual y natural (Juan Manuel) o hechos de armas y de caballería (Pedro Afonso). La mención de estos campos del conocimiento, y la renovada importancia que adquieren en el quehacer historiográfico, evidencia que sus autores reinterpretan el propósito prologal de Alfonso X, reorientándolo para responder a nuevas ideologías y realidades políticas. ${ }^{14}$

\section{LA ReESCRitura de LA Historia En la CRóNICA ABREVIADA}

Para determinar cómo Juan Manuel reformula el material y el propósito de la historia alfonsí, se deben identificar las continuidades y las discontinuidades entre la crónica y la $E E$, prestando atención a los lugares donde las historias divergen. En el siguiente análisis se establecen los efectos de la abreviación sobre el material alfonsí y postalfonsí al: 1) reducir el accionar de los reyes y erosionar el discurso monárquico, 2) amplificar los vicios de los reyes y convertir a la nobleza en una fuerza de control de sus excesos y 3 ) destacar las acciones y las virtudes de ciertos defensores, que se convierten en modelos de buen comportamiento social.

Para disminuir la extensión de la EE, la Crónica abreviada suprime numerosos capítulos de los dos primeros libros de la $C M$ que van desde la creación hasta la muerte de Vermudo III de León. Curiosamente, estas son las secciones que reflejan más fielmente el estilo "complido" alfonsí, pues vienen de la Versión primitiva de la $E E .{ }^{15}$ En general, hay una simplificación sustancial de los elementos considerados superfluos: se elimina la sincronización del cómputo cronológico alfonsí, junto a casi la totalidad de eventos míticos, razones, narraciones milagrosas, relatos o tramas políticas secundarias. Esto hace que la crónica se asemeje más a los parcos anales latinos que a la $E E$, enumerando año por año los hechos más importantes de cada reinado, pero sin abundar en detalles. En esta narración emergen dos fuerzas contrapuestas: los reyes y los nobles.

Si para Alfonso X la historia de España hasta los godos es una sucesión de entes políticos articulados en torno a figuras regias (príncipes, reyes o emperadores), cuyas acciones interesan por su capacidad de prefigurar la restauración del señorío que llegaría en la narración de los hechos de su reinado (Fernández-Ordóñez, 2000c), en la abreviación, la historia antigua se vuelve una sucesión de monarcas que sufren malas muertes al ser corrompidos por los vicios comúnmente atribuibles a quienes comandan el poder. Las eliminaciones develan estructuras repetitivas ocultas tras los largos capítulos alfonsíes. Juan Manuel construye un largo ubi sunt que recuerda las muertes regias, causadas por conjuras nobiliarias o por el castigo divino, y las entronizaciones de sucesivos emperadores y reyes: “después de la muerte de Juliano alçaron los romanos por emperador a Joviniano e regnó ..." (2007, p. 132), "después de la muerte de Gundemaro alçaron los godos por rey a Sisibuto e regnó ..." (2007, p. 162). 
Los eventos más significativos de la $E E$, la caída del reino godo y el lamento por la pérdida de España, son casi completamente borrados por un cronista al que parecen poco importarle tales sucesos cataclísmicos: "En el capítulo CVI dize el llanto de España. Otrosí dize que los reyes de los godos morieron muerte desaguisada" (2007, p. 177). ${ }^{16}$ Creo que esta actitud se debe a que, a lo largo de la abreviación de los primeros dos libros, los reyes emergen como figuras dudosas, dedicadas "a vicio e a folgar e a usar todas malas costumbres" (2007, p. 119), y no tanto a desarrollar políticas que favorezcan a los reinos y a sus vasallos, como se comprueba en las narraciones de los hechos de Tiberio, Nerón y Domiciano en el periodo romano, Witiza en el godo y Ordoño II y Fruela II en la historia asturleonesa. Pocos son los casos de figuras regias cuyas acciones son destacables, como Julio César, Octaviano o Bamba.

Por contraparte, la aristocracia es una fuerza dinamizadora en los sucesos narrados. Mientras la moralmente decadente, inmovilizada y poco efectiva monarquía recorre un espiral descendente, lo opuesto sucede con senadores, cónsules, caballeros y nobles, quienes asumen tareas de gobierno y son responsables de reemplazar a los reyes. Así ocurre con Domiciano, cuya conducta origina su muerte por decisión del senado: "Otrosí dize qu'el senado, viendo cómo este emperador era muy malo, llegaronse e dieron por sentencia que.l matasen e mató.l un su castrado" (2007, p. 109) o, ya en la historia castellana, con los jueces de Castilla, Nuño Rasuera y Laín Calvo, quienes representan a una nobleza comprometida con la educación y el ordenamiento del condado: "E porqu'el rey don Ordoño les avía muerto sus condes, fizieron dos juezes, non de los más poderosos mas de los más sesudos, que ordenasen e mandasen todos los fechos de la tierra” (2007, p. 202).

Esto lleva al segundo efecto de la abreviación: la transformación de la nobleza en una fuerza que mantiene a raya los excesos regios, acción que puede ocurrir de dos maneras. La primera es mediante la omisión y la alteración de pasajes que presentan a nobles actuando en contra del pueblo o del orden social. En la $E E$, la caída de Cartago es el nudo narrativo que culmina la descripción de la campaña pacificadora de Escipión Emiliano, pero también certifica los abusos cometidos por los romanos contra los pueblos ibéricos, pues durante esta expedición destruyen Numancia. El sentido de esta sección debe ser interpretado a la luz de una advertencia del prólogo: "E esto fiziemos porque fuesse sabudo el comienço de los españoles e de cuáles yentes fuera España maltrecha (...) E las mortandades que los romanos fizieron en ellos e los destruimientos que les fizieron" ( $E 1$, fol. 2vb). Esta guía hermenéutica es reforzada y enfocada directamente sobre la campaña del Emiliano en el lamento de España, donde se recuerda "cuánto mal sufrió aquella noble Cartagena cuando la prisó e la quemó Cipión, cónsul de Roma” (E1, fol. 193vb).

Tras un largo sitio, los cartaginenses aceptan los términos ofrecidos por Escipión y abandonan la ciudad junto al rey Asdrúbal. Sin embargo, un pequeño grupo de cartaginenses se refugia en un templo, que es rodeado por los romanos e incendiado para forzar su rendición. Pero los rebeldes prefieren arrojarse al fuego. Lo mismo sucede con la esposa de Asdrúbal y sus dos pequeños hijos. En vez de entregarse, la reina busca santuario en una torre que también es cercada e incendiada. No dispuesta a rendirse, escala hasta la cima junto a sus hijos y, tras dirigirse a las fuerzas conquistadoras, se arroja con ellos a las llamas. Los horrorizados soldados intentan salvarla, pero llegan muy tarde. Ante el pavor de los romanos, conscientes de su responsabilidad compartida en el regicidio, la $E E$ contrapone la frialdad del cónsul, quien inmediatamente ordena prender fuego a toda la ciudad: "E Cipión, que grant sabor avié de destruir aquel lugar por crecer el poderío de los romanos e por vengarse de los grandes daños que allí recibieran, mandó encender la cibdat de todas partes e duró ardiendo xvii días" (Q, fol. $35 \mathrm{vb}) .{ }^{17}$

La Crónica abreviada describe el sitio y la destrucción de Cartago brevemente: "E [Cipión] vino ý e falló seguros los de la cibdat e cercola e al cabo entrola por fuerça e quemola e destruyo la toda" (2007, p. 85). Este pasaje es seguido por una omisión de dos capítulos, donde deberían relatarse los detalles de la caída de la ciudad. En vez de abreviarlos, el compilador los elimina y escribe: "non fallamos ninguna cosa que cumpla poner en este libro" (2007, p. 85). A diferencia del texto alfonsí, el compilador no tiene palabras de crítica sobre la descontrolada sed de venganza del cónsul o las barbáricas acciones de sus soldados. ${ }^{18}$ 
Algo similar sucede durante la narración de la traición de Bruto y Casio, magnicidio que en la $E E$ es secundado por doscientos sesenta nobles romanos, pero que en la crónica es acompañado por un genérico grupo formado por "otros cavalleros romanos" (2007, pp. 96-97). ${ }^{19}$ Tras la muerte de Calígula, la historia alfonsí describe los conflictos entre los senadores, los cónsules y el pueblo romano sobre la elección de un nuevo emperador o el retorno a la aristocrática forma de gobierno anterior, la república senatorial. ${ }^{20}$ Los primeros sostienen que el senado previene los abusos y la decadencia moral de los emperadores. El pueblo romano, apoyado por la caballería, rechaza esta propuesta; los ciudadanos temen la codicia de los nobles y recuerdan las buenas acciones de los emperadores. Esta visión se impone a la propuesta aristocrática y se reinstaura el gobierno imperial, con Claudio a la cabeza. La oposición entre la nobleza y el pueblo es borrada en la crónica, manteniéndose solo el núcleo de la historia: "llevantose muy grant desabenencia en Roma, ca los unos querían emperador e los otros non e dizién que non oviesen emperador. Pero al cabo fizieron emperador a Claudio" (2007, p. 104). ${ }^{21}$

Otro caso de protección de figuras aristocráticas ocurre en la historia castellana, durante el episodio de Fernán González y el mal arcipreste. En la EE, el conde y la infanta Sancha huyen de García Sánchez I de Pamplona usando el camino francés, donde son encontrados por un arcipreste. El clérigo amenaza con que, si Sancha no se acuesta con él, revelará el paradero de los prófugos a los soldados del rey. Aunque el conde se escandaliza, la infanta accede al pedido: "ca por esto non queremos nós morir nin perder el condado" ( $T$, fol. 160rb). Mientras el religioso se está desvistiendo en un lugar alejado, la infanta le ataca sorpresivamente: "travó d'él a la boruca e dio.l una grant tirada" ( $T$, fol. 160rb). Fernán González llega a ellos "con un cuchillo en la mano e matáronle allí amos ados" ( $T$, fol. 160va).

Hay varios elementos que dejan muy mal parado al conde y a su futura esposa. El arcipreste los trata inicialmente como criminales: "itraidores!, non vos podedes ya ir nin podredes escapar de la mano del rey" ( $T$, fol. 160ra). El engaño diseñado por Sancha pone en tela de juicio su honor, al utilizar un proverbio de origen bíblico para sostener que el pecado es preferible a la muerte: "ca mucho valdrá más que partamos el pecado nós todos tres” ( $T$, fol. 160rb). ${ }^{22}$ Más problemático aún es que la afrenta del arcipreste paralice a Fernán González y que este solo responda con palabras: "Cuando el conde le oyó dezir cosa tan sin razón e tan sin guisa, pesó.l más que si.l diesse una grant lançada e dixo.l qu'él demandava cosa muy sin guisa e sin razón, e que querié grand soldada por poco de trabajo" ( $T$, fol. 160rb). Esta pasividad es resuelta por la sugerencia de la infanta de que ella y el arcipreste se desnuden lejos del conde para evitar la vergüenza: "mas á menester que nos apartemos amos a un lugar ó el conde non nos pueda ver, ca avrié por ende grant pesar" ( $T$, fol. 160rb). Finalmente, está la acción más reprensible, el asesinato a traición, del que no se vuelve a hablar en la $E E$ y que en la Versión retóricamente amplificada es realizado con un arma robada: "e llegó el conde con el su cuchiello del arcipreste en la mano e matáronle allí amos a dos" (E2, fol. 70rb).

Morrison (1935) nota que en la crónica toda la acción es eliminada, ausencia que Benito-Vessels (1994) duda entre atribuir al compilador o al modelo de la $C M .^{23} \mathrm{Al}$ no sobrevivir la sección en el manuscrito que transmite esta última, solo es posible conjeturar. Me inclino por atribuir la omisión al compilador juanmanuelino por dos razones. La primera se basa en indicios manuscritos: todas las ramas conocidas de la $E E$, alfonsíes y postalfonsíes, mantienen el episodio con variaciones menores. Aparece en la rama vulgar y la rama regia de la Versión primitiva, en la Versión critica y en la Versión retóricamente amplificada, e incluso en la Crónica geral de 1344. Su persistencia demuestra cierto interés entre los historiadores - y quizá los lectores - por este tipo de narraciones con elementos folclóricos, a pesar de sus implicaciones morales, lo que hace poco probable que la $C M$ no lo transmitiera. ${ }^{24}$ La segunda razón tiene que ver con el ya evidente sesgo nobiliario de la crónica de Juan Manuel. Como ocurre en las abreviaciones de los pasajes sobre Escipión y Julio César, la eliminación de esta sección es una manifestación de las decisiones editoriales de un compilador que suaviza u omite materiales que reflejan negativamente sobre los nobles. 
El mismo procedimiento se aplica a un relato de los reinados de Enrique I y Fernando III de la CM. Durante el breve reinado en minoridad de Enrique I de Castilla, los condes Álvaro, Fernando y Gonzalo Núñez de Lara intentaron hacerse con la tutoría regia, en un conflicto con Berenguela de Castilla que es largamente descrito en esta crónica. Después de la accidental muerte del infante rey, Berenguela cede el trono a su hijo, Fernando III. A pesar del coronamiento del nuevo rey, los Lara mantienen sus acciones rebeldes. La CM presenta estos eventos desde una óptica afín a Berenguela. Se refiere a ella como reina — un título que el Toledano le da por su matrimonio con Alfonso IX de León- y como una mujer "muy sabidora de los bollicios del mundo" $(\mathrm{Br}$, fol. 190v) y "sabia e entendida en las cosas" ( $B r$, fol. 191v). ${ }^{25}$ Por oposición, los condes son movidos por el deseo de "vengar la malquerencia que tinién en los coraçones" ( $B r$, fol. 190v).

Tras algún tiempo, Fernando III logra arrinconarlos y vencerlos. La muerte de los dos primeros se inspira en una historia milagrosa descrita por el Toledano, amplificada para servir como ejemplo de cómo Dios actúa contra los revoltosos nobles. ${ }^{26}$ Tras enfermar, el conde Álvaro es llevado a Toro "medio muerto" ( $\mathrm{Br}$, fol. 196r)y, anticipando su fin, toma el hábito antes de morir: "cuando vio que ningún acorro non podié aver de ninguna parte diose a la cavallería de Santiago e metiose en esa orden” ( $\mathrm{Br}$, fol. 196r). También aceptando su derrota, el conde Fernando se exilia a Marruecos: "pues que non vio en el reino de Castilla lo que él deseaba, pasó la mar e fuese para África, a Marruecos al Miramamolín” ( $B r$, fol. 196r). Ahí, se pone al servicio del califa almohade Yusuf al-Mustansir, hijo del al-Nasir vencido en Las Navas de Tolosa, batalla en la que los Lara habían participado por el bando cristiano. El califa:

recibiolo e diole soldada e sus dones otros. E contando el conde don Fernando sus fechos allá de unas maneras e de otras, e alabándose todavía, traxéronle los moros luengo tiempo a unas e a otras partes, faziéndole solazes e plazeres como diz que es su costumbre de los alárabes, tanto que andando en esto acaeció al conde don Fernando que enfermó de muy gran enfermedad (...) e pues que vio que la enfermedad de muerte era (...) tomó el conde don Fernando de aquel frey Gonçalo el ábito del Ospital e entró en esa orden del Ospital e ý murió. ( $B r$, fol. 196r)

Que ambos condes tomen hábitos religiosos antes de morir, siguiendo una costumbre extendida entre los reyes y los nobles en los siglos XIII y XIV, no implica su arrepentimiento, todo lo contrario: el fin devocional de la ordenación es subvertido por hombres que intentan escapar de la justicia. La muerte del conde Fernando es un doble castigo: por rebelarse contra dos legítimos reyes de Castilla y por actuar contra Dios, al ponerse al servicio de un enemigo de la fe (el califa almohade) y vivir, como juzga el cronista, una vida de placeres siguiendo la ley musulmana.

Como es esperable, todo esto desaparece en la Crónica abreviada. El compilador se limita a contar las aparentemente pías muertes de los condes: "E adoleció el conde don Álvaro e murió en Toro, pero ante que muriese recibió el ábito de Santiago (...) el conde don Fernando passó la mar con miedo del rey e morió en Marruecos, pero ante que moriese recibió el ábito de san Joán” (2007, p. 279). El cronista también elimina el elemento milagroso de la muerte de don Álvaro y omite el juicio sobre el escandaloso exilio en la corte almohade de don Fernando, que queda justificado por su "miedo del rey" (2007, p. 279). Pero la abreviación nobiliaria no intenta justificar las acciones de los condes ni exonerar sus crímenes; solo algunas páginas antes son descritos como figuras desestabilizadoras del orden social: "E luego que ovieron la guarda [del rey don Enrique] salieron andar con él por la tierra e fazién mucho mal a los que querién" (2007, p. 277).

Saracino (2013 y 2014) explica que para los cronistas postalfonsíes la rebeldía nobiliaria puede ser una característica positiva o negativa, dependiendo del contexto en el que ocurre. A pesar de que las acciones de los condes en la Crónica abreviada son negativas, hay muchos otros ejemplos de rebeldía positiva, como el Cid, Fernán González o Bernardo del Carpio, con los que se construye un sistema de valores caballeresconobiliario. Si la relativa cercanía temporal de los eventos que involucran a los Lara, y que sus acciones se dirijan contra Fernando III, abuelo de Juan Manuel, hace imposible reescribir la historia y exonerarlos, esto sí ocurre en capítulos del pasado antiguo de la Península y de la historia heroica de Castilla. En ellos se manifiesta el segundo efecto de la abreviación sobre su modelo, convirtiendo a la nobleza en un mecanismo de control 
de los abusos regios que protege sus intereses sociales, y por extensión los de toda la sociedad, y al ofrecer su consilium a los reyes.

Un ejemplo singular se da en la materia romana. La EE describe a Probo como un emperador "muy derechurero e muy noble en todos sus fechos e que semejava a Aureliano en su buena nombradía” ( $Q$, fol. $127 \mathrm{rb}$ ), capaz de pacificar rápidamente todas las provincias romanas tras acceder al trono. ${ }^{27} \mathrm{~A}$ pesar de que su reinado inaugura un periodo de bienestar político y social, Probo tuvo constantes desavenencias con los nobles porque era incapaz de soportar "las loçanías e los desdenes de los cavalleros" ( $Q$, fol. 127va). Para mantener a raya a los defensores en tiempos de paz, los hizo satisfacer un curioso interés suyo: sembrar vides. La prosperidad alcanzada durante su reinado, la ausencia de conflictos internos o externos y la ociosidad de los ejércitos le llevaron a sostener, infelizmente, que "a poco tiempo non serién menester los cavalleros en la tierra” ( $Q$, fol. $127 \mathrm{va}$ ). Como es esperable, tales palabras no fueron bien recibidas por los nobles, quienes rápidamente lo asesinaron. Del emperador jardinero de la $E E$, figura construida mediante amplificaciones de la Historia de Eutropio, la crónica ofrece una lectura muy diferente: "E porque non avía menester los cavalleros, fazíales poco bien e por esta razón matáronle" (2007, p. 121). El justo Probo es convertido en un rey que ataca a los defensores romanos, quienes no tienen otra alternativa que rebelarse para proteger sus derechos.

Una alteración similar se observa en los capítulos relacionados con la batalla de Roncesvalles. La $E E$ relata que Alfonso el Casto intenta forjar una alianza con Carlomagno para frenar el avance de los ejércitos omeyas, llegando a ofrecerle su trono como contrapartida a su apoyo militar:

Pues que vio que era viejo e de muchos días embió su mandadero en poridat a Carlos emperador de los romanos e de los alemanes e rey de los franceses, [e dixo que] como él non avié fijos e si.l quisiese venir ayudar contra los moros que.l darié el reino. (E2, fols. 19rb-19va)

Al enterarse de esta embajada, los nobles asturianos, liderados por Bernardo del Carpio, dan un imperioso consejo al rey: "que revocase lo que embiara dezir al emperador si non que.l echarién del reino e catarién otro señor, ca más querién morir libres que ser mal andantes en servidumbre de los franceses”. (E2, fol. $19 \mathrm{v}_{\mathrm{a}}$ ). Los historiadores alfonsíes proponen de esta manera que los nobles cumplen con sus deberes estamentales: recuerdan al rey su obligación de mantener el reino y defienden la tierra de sus enemigos (musulmanes o cristianos). En la crónica se elimina la segunda parte del consejo y se altera ligeramente lo dicho por la $E E$ : "E los españoles, cuando supieron esto dixeron al rey que revocase el mandado si non que.l echarían del regno" (2007, pp. 190-191). La abreviación da la impresión de que los nobles son responsables de determinar cuáles son las condiciones necesarias para ocupar el trono y cuándo este debe ser vacado. El pasaje también recupera una estructura utilizada algunos capítulos antes, durante la entronización de Alfonso: "después que fue muerto Silo alçaron los de la tierra por rey a don Alfonso por consejo de la reina doña Usenda" (2007, p. 187). Estos cambios alteran el sentido del triunfo de los ejércitos asturianos en Roncesvalles. Si en la $E E$ la victoria es una demostración del señorío de la tierra asumido por el rey, en la crónica lo es del buen consejo de la nobleza y de su capacidad para controlar las imprudencias regias.

En la historia contemporánea de Castilla este tipo de operaciones se vuelve más sutil. El cronista deja de eliminar contenido y comienza a trasponer sentidos, desplazando acciones y características que su modelo atribuye a los reyes en favor de los grandes señores de la aristocracia castellana. La $C M$ relata que los nobles castellanos y leoneses temen los efectos de la guerra entre Alfonso VIII y Alfonso IX de León sobre sus poderes y sus tierras, amén de la mengua de sus números. Los magnates conciben una alianza matrimonial para terminar el conflicto:

Unos de los grandes omes de los reinos, temiendo de los daños e peligros de la guerra, metiéronse en medio e fallaron carrera de abenencia e de amor e que podría esto venir por casamiento. [E] metiéronse a consejar que dixesen a la reina que consejase al rey don Alfonso su marido que diese al rey don Alfonso de León a su fija la infanta doña Berenguela por muger. ( $B r$, fol. $172 \mathrm{v}$ ) 
Los nobles acuden luego a la reina Leonor de Plantagenet y le encargan la tarea de convencer a Alfonso VIII de firmar la paz:

E así como se pudo apartar con el rey, fabló en este casamiento con él, e cuando le mostró los bienes que por ello vernién en las gentes e los males que por ay se desviarién e sobre eso tanto le sopo de falagar de sus palabras e adulcearle que gelo ovo de otorgar que se faría el casamiento. ( $B r$, fol. $173 r$ )

Aunque los historiadores postalfonsíes, que siguen al Toledano, describen positivamente la alianza de la que nace el rey unificador, Fernando III, no ocultan sus críticas al motivo que impulsa a los nobles a actuar. No son guiados por su preocupación por el bienestar del reino, sino por temor a cumplir con sus obligaciones estamentales, "temiendo los daños e peligros de la guerra" ( $B r$, fol. 172v). El mérito del matrimonio recae principalmente sobre la reina, "muy sabia e muy entendida dueña e avisada e [que] entendié en los peligros de las cosas e las muertes de las gentes que vernién en este desamor" ( $B r$, fol. 172v). A diferencia de los nobles, Leonor actúa por amor al pueblo y cumpliendo su deber como reina. La conversación con su esposo también refleja otras cualidades positivas que se le atribuyen, como su inteligencia y esmerada educación, que le permiten construir un discurso adornado de recursos retóricos con el que convence al rey.

En la Crónica abreviada, la responsabilidad del matrimonio es desplazada de la reina a los aristócratas castellanos, quienes actúan preocupados por la paz y el orden social. La reina queda desprovista de toda capacidad de decisión y agencia y se convierte en un peón de la nobleza:

Fablaron los altos omnes de la tierra con doña Leonor muger del rey don Alfonso de Castilla, e mostrando.l cuántos daños e cuántos males vinién al regno de Castilla de la guerra del rey de León e, si podiese ser, que era bien de aver pazes con el rey de León e para esto que casasen con él a la infanta doña Beringuela.E la reina veyendo que era bien fabló con el rey don Alfonso e feziéronlo ansí, e viniéronse los reyes en uno e posieron sus pazes. (2007, p. 271)

Cuando los nobles acuden a Leonor en la $C M$, su entendimiento le permite comprender los peligros que se ciernen sobre el reino: "fablaron con ella en poridad e en tal manera le dixeron la razón (...) [e] la reina, como era mucho sabia e de gran entendimiento (...) cuando oyó de los omes buenos tantas buenas razones, otorgóles que le plazié de coraçón" (fols. 172v-173r). Por comparación, en la Crónica abreviada los nobles tienen que explicarle cuáles son los efectos negativos de la guerra, en un gesto paternalista que la desprovee de toda la autonomía que sí tiene en su modelo: "mostrando.l cuántos daños e cuántos males". El cronista se asegura de que la responsabilidad de la paz, y por tanto, de la futura unificación de los reinos, recaiga sobre la aristocracia.

Este episodio me lleva al tercer efecto de la abreviación en la construcción del discurso nobiliario de la Crónica abreviada, la amplificación de las virtudes y las acciones de algunos defensores notables. Habiendo ya discutido pasajes concernientes a Fernán González y Bernardo del Carpio, limitaré esta discusión a la figura histórica en la que Juan Manuel encontraría mayores similitudes con su condición vital, y que acaso resultara más atractiva para establecer un conjunto de valores y comportamientos aristocráticos: el Cid. En la $E E$, tras repartir su reino entre sus hijos, Fernando I llama al Cid "e comendó.l sus fijos e sus fijas que los consejasse bien e toviesse con ellos do mester les fuesse" (E2, fol. 140ra). Es innecesario explicar que se trata de un ejercicio de sumisión del caudillo a sus deberes de auxilium y consilium. En la crónica, por oposición, estos roles se invierten. Fernando I le demanda a sus hijos que confíen en el consejo del Cid, "que quisiesen creer al Cid Roy Díaz de lo que les consejase" (2007, p. 228), atándolos a las buenas razones del vasallo.

La crónica sigue a su modelo en la descripción de las luchas fratricidas entre los hijos de Fernando I, pero vuelve a alejarse de este tras la conquista de Toledo, hecho que marca la consolidación del poder de Alfonso VI. La abreviación es especialmente selectiva en la materia relacionada con el asedio y la rendición de Valencia. Del largo sitio, las negociaciones entre cristianos y musulmanes y los fallidos intentos de Ibn Yahhaf por lograr que los almorávides acudan a su defensa, eventos que ocupan varios capítulos en la $C M$, el cronista de Juan Manuel selecciona aspectos de interés para un señor de la frontera: qué técnicas militares se emplean en el asedio y cómo el Cid reorganiza la ciudad tras la conquista. ${ }^{28}$ 
El cronista continúa transformando la narración sobre el Cid para reflejar mejor su visión nobiliaria de la historia. El defensor ideal y virtuoso es perfectamente descrito en el conocido relato de la embajada del sultán de Persia introducido por la Interpolación cidiana de la *Estoria caradignense del Cid. Según la CM, el sultán envía un familiar como mensajero:

Cuando fue otro día de gran mañana cavalgó el Cid e con él toda su compaña muy noblemente vestidos e sus cavallos ante sí e sus escuderos que le llevavan las armas empós de sí, e non eran tan pocos que non fuesen de mil e quinientos arriba. $\mathrm{E}$ cuando llegaron cuanto a tercio del agua del puerto e los vio aquel pariente del gran soldán de Persia fue muy pagado de cuán apuestamente venién e allí vio e entendió cuán noble ome era el Cid Campeador. E cuando el Cid vio que era cerca aquel pariente del soldán, paró el su cavallo Babieca e començolo a esperar. E cuando el pariente del soldán fue muy cerca del Cid e le tovo ojo, començole a tremer toda la carne e él mismo fue maravillado de que le tremía así su carne e tovo ojo otra vez al Cid. E el Cid fuelo por abraçar e aquel moro pariente del soldán no le pudo fablar fasta una gran pieça pasada (...) e cada vez que el Cid se tornava para fablar con aquel pariente del soldán, siempre le vinié en miente en cómo le tremiera la carne e perdiera la fabla de la primera vez que le viera. E quisiéragelo preguntar al Cid, mas nunca se atrevió a gelo dezir pero que lo tovo siempre en coraçón. ( $B r$, fols. $124 \mathrm{r}-124 \mathrm{v})$

Más tarde, el almojarife del Cid le explica al emisario que Dios le ha dado a su señor tal semblante que todos los mensajeros musulmanes que lo ven pierden el uso de la razón, "fincan desacordados catándole, [ca] tan gran miedo an de la su catadura" ( $\mathrm{Br}$, fol. $125 \mathrm{r}) .{ }^{29} \mathrm{La}$ Crónica abreviada introduce una ligera, aunque significativa, alteración:

Otrossí dize que cuando aquel pariente del soldán vino primeramente al Cid començó a tremer e estudo una grant pieça que non pudo fablar. E esto era por virtud que pusso Dios en el Cid que nunca moro le vio primeramente que.l non acaeciesse esso mesmo. (2007, pp. 254-255)

El cronista incluye en este capítulo un juicio que el almojarife da en un capítulo diferente en la $C M$. Tal desplazamiento construye una poco común reflexión sobre la universalidad de la virtud divina del héroe, sostenida, ya no por las palabras de un sirviente, sino por la autoridad del cronista, enunciador de la historia. Otro cambio ocurre respecto a la capacidad del Cid de infundir temor, que ahora no se limita a los mensajeros, sino que alcanza a todos los musulmanes. De la abreviación y la alteración del material emerge una figura revestida de un aura milagrosa, que se aleja un tanto de la tradición histórica y se acerca más a las descripciones fantásticas que se encuentran en la épica (por ejemplo, en el episodio del león del Poema) o en las narraciones hagiográficas incorporadas en escritos postalfonsíes (como el milagro de las barbas de la Interpolación cidiana). El efecto de tales proezas sobrehumanas en la Crónica abreviada es una figura idealizada del defensor, erigido como un contrapeso nobiliario a los habitualmente envilecidos reyes (Benito-Vessels, 1994).

Habiendo discutido hasta aquí los efectos aristocratizantes de la abreviación sobre la materia alfonsí y postalfonsí, creo necesario aclarar que no todos los eventos narrados en la Crónica abreviada pueden o deben interpretarse como signos de pertenecer a un manifiesto señorial o reflejar un programa nobiliario. Cuando la crónica comienza a adentrarse en la historia contemporánea de Castilla, el compilador va renunciando progresivamente a la visión señorial que ha desarrollado en los primeros dos libros. Esto ocurre porque el tercer libro de la $C M$ deja de ofrecer material que puede ser reformulado desde la óptica de la nobleza. Consecuentemente, el compilador deja de apartarse de la historia alfonsí y comienza a reinterpretarla dando una apariencia de continuidad (Saracino, 2006).

Desde el reinado de Alfonso VIII, la EE que Juan Manuel conocía, en realidad ya producto de redacciones postalfonsíes, cambia sustancialmente. En la historia comienzan a ser más protagónicos los eventos que involucran a los nobles, especialmente las rebeliones señoriales, causadas por una aristocracia que aspira a ocupar un rol más importante en la administración del reino. Estos desencuentros son utilizados por el compilador para ofrecer modelos de buen comportamiento cortesano. Ya no se eliminan pasajes críticos con la nobleza; antes bien, son utilizados para amparar las decisiones de reyes excepcionales que protegen la unidad del reino y los derechos de la tierra de las acciones de malos nobles, cuyo único interés es amasar poder. Así son descritos los conflictos entre los Lara y los Castro durante la minoridad de Alfonso VIII y 
las desavenencias de este rey con el señor de Vizcaya Diego López de Haro. Tampoco se omite el "bollicio" causado por los hijos de Nuño Pérez de Lara para obtener la tutoría de Enrique I.

Coincidiendo con este cambio, la Crónica abreviada comienza a realzar el virtuosismo de los reyes castellanos, especialmente de Alfonso VIII y Fernando III, cuyos comportamientos y valores son afines a la moral caballeresca de Juan Manuel. Varios capítulos sobre Alfonso VIII son reveladores por su contenido. Así sucede en el inusualmente largo capítulo que relata las cortes de Carrión de 1188, en el que se ensalza la figura del rey como caballero y señor de la caballería, al hacer caballeros a Alfonso IX de León y Conrado de Suabia, hijo de Federico I Hohenstaufen. Otra amplificación moral ocurre durante las preparaciones de los ejércitos cristianos antes de Las Navas de Tolosa. Siguiendo al Toledano, la CPSF lee:

El rey don Alfonso (...) desque ovo todas estas cosas puestas e paradas con todas estas yentes de la guisa que avemos contado, mandó a sus notarios e a los escrivanos que sopiessen de las yentes trasmontanas la cuenta cuántos eran peones e cavalleros, e dize el arçobispo don Rodrigo que fallaron ý de los de allén de los montes de fuera de España, de cavalleros más de X mil e de omnes a pie sobre cien vezes mil, e pero segund la estoria quiere dezir que los de fuera de Castiella, como aragoneses, leoneses, gallegos, portugaleses e asturianos, que en esta cuenta entraron de los $\mathrm{X}$ mil cavalleros e de los cien vezes mil omnes a pie. E el noble rey don Alfonso cogiosse estonces a su palacio e penssó e mandó echar pregón por toda la hueste (...) (E2, fol. 298ra-b)

\section{Por contrapartida, en la Crónica abreviada:}

E el rey don Alfonso, por saber qué gentes avía ý fuera del su señorío fízolas contar e falló que eran X mil omnes a cavallo e cien vezes mil omnes de pie, e estos sin los de Castilla. E este rey don Alfonso, como le dio Dios complido entendimiento sobre todos los omnes del mundo, fabló con todas estas gentes con cada una d'ellas a su parte, en guisa que todos fueron muy sus pagados e dixeron que todos morrían o vencerían con él. E mandó luego echar pregón por la hueste (...) (2007, p. 273)

El material nuevo ("E este (...) con él”) es una abreviación parcial de la descripción de las reuniones del rey con las diferentes fuerzas que conforman su ejército, pasaje que aparece poco antes del relato del cómputo de las fuerzas en la CPSF. Sin embargo, al abreviar y trasponer el lugar de la narración, el cronista crea un discurso que parece sugerir que Alfonso VIII no solo fue el líder de un gran ejército cruzado, sino un monarca poligloto y entendido en todas las culturas de la cristiandad, forma de universalismo comparable al que se adscribe al Cid.

Gracias a que la CPSF es la fuente de los capítulos sobre Fernando III en la CM, el compilador de la Crónica abreviada pudo extender su relato hasta la muerte del rey. Esta narración no solamente cierra la historia contemporánea del reino, sino que da inicio a la historia familiar del autor. La muerte de Fernando III es un nudo semiótico que sintetiza la visión de la legitimidad dinástica que Juan Manuel desplegará en sus siguientes obras (Cossío Olavide, 2022a). En la CPSF, el rey moribundo convoca a sus hijos y:

\footnotetext{
Primeramente fizo acercar a sí [a] don Alfonso su fijo e alçó la mano contra él e santiguolo e dio.l su bendición e de sí a todos los otros sus fijos. E rogó a don Alfonso que llegase sus hermanos a sí e los criase e los mantoviese bien e los levase adelante cuanto podiese e (...) [rogó.l] por todos los ricos omnes de los sus regnos e por los cavalleros, que los onrasse e les feziese siempre algo e merced e se toviese bien con ellos e les guardase bien sus fueros e sus franquezas e sus libertades todas a ellos e a todos sus pueblos. E si todo esto que él encomendava e rogava e mandava compliese e lo feziese así, que la su bendición complida oviese e si non la su maldición. E fizoll responder: "Amén". (E2, fol. 358va) $)^{30}$
}

Esto es resumido muy fielmente en la Crónica abreviada, aunque con una diferencia importante

E fizo llegar ante sí a su fijo don Alfonso e mandó.l e rogó.l que (...) criase sus hermanos e los mantoviese e los levase adelante cuanto podiese e rogó.l (...) por todos los ricos omnes e cavalleros de sus regnos, que les fiziese mucha onra e los mantoviese e les feziese algo, en guisa que podiessen muy bien pasar, e que les guardase sus fueros e sus libertades a ellos e a todos sus pueblos. E dixo.l que si esto ansí feziese que.l dava la su bendición e si non que.l dava su maldición. (2007, p. 296)

En la Crónica abreviada, Alfonso nunca acepta las condiciones establecidas por su padre para recibir su bendición: mantener los estados de sus hermanos y los fueros de la nobleza y de los pueblos. Esta aprobación sí existe en el "Amén" de la CPSF. A pesar de esto, la crónica de Juan Manuel relata que el rey muriente bendice a su hijo: "Dessí santiguó.l e dio.l su bendición" (2007, p. 296). Estos hechos se conectan con algo 
que el autor de la crónica sostiene en el prólogo sobre Alfonso X, quien "era alumbrado de la gracia de Dios para entender e fazer mucho bien", pero

por los pecados de España e por la su ocasión e señaladamiente de los que estonce eran e aún agora son del su linage, ovo tal postrimería que es quebranto de lo dezir e de lo contar. E siguiosse ende tal daño que dura agora e durará cuanto fuere voluntat de Dios. (2007, p. 68)

Es probable que la mención a los pecados del reino y de Alfonso sea evidencia de un relato oral conocido por Juan Manuel, que sostenía que, a pesar de su gran conocimiento y amor por el saber, los muchos desmerecimientos y la soberbia del rey originaron una maldición divina que aún pesaba sobre su linaje. Esto es sugerido en el prólogo del Libro de la caza (2011), que lo describe como un rey alumbrado: "non podría dezir ningún omne cuánto bien este noble rey fizo señaladamente en acrecentar e alumbrar el saber" (p. 129), pero también castigado por la ira divina:

¡O Dios Padre e criador e poderoso e sabidor sobre todas las cosas: bendicho e loado seas tú de todas las criaturas e especialmente quieras que te loen en buenas obras e en buenas voluntades las criaturas razonables que tú señaladamente crieste para te conocer lo que de ti se puede alcançar e para te loar; e marabillossos e derechureros son los tus juizios e marabillosso fue el que vino contra este tan noble rey! Tú, Señor, sabes lo que feziste. Bendito seas tú por cuanto feziste e cuanto fazes e por cuanto farás. (pp.129-130 $)^{31}$

Las alteraciones de la historiografía alfonsí y postalfonsí discutidas hasta aquí son las semillas de un contradiscurso a la legitimidad de la dinastía de Alfonso. Juan Manuel lo continuará desarrollando, silenciosamente, en sus siguientes obras, y volverá a surgir declaradamente en uno de sus últimos libros, el Libro de las tres razones (Funes y Qués, 1995). Ahí, ya sin tapujos, le atribuye a un falleciente Sancho IV un relato que reescribe desafiantemente el final de la $C P S F$, que él creía la $E E$, confirmando la maldición de Alfonso X:

- Yo non vos puedo dar mi bendición que non la he [de míos padres]; ante, por míos pecados e por míos malos merecimientos que les yo fiz ove la su maldición. E diome la su maldición mío padre en su vida muchas vezes seyendo bivo e sano e diómela cuando se moría (...) e aunque me quisieran dar su bendición non pudieran, ca ninguno d'ellos non la heredó nin la ovo de su padre nin de su madre, ca el santo rey don Ferrando mío abuelo non dio su bendición al rey mío padre sinon guardando él condiciones ciertas que él dixo. E él non guardó ninguna d'ellas e por esso non ovo la su bendición (...) E só bien cierto que la avedes vós complidamente de vuestro padre e de la vuestra madre, ca ellos heredáronla de los suyos.

E contar vos he cómo la ovo vuestro padre del rey don Ferrando nuestro abuelo. Cuando el rey don Ferrando finó en Sevilla (...) dio.l la su bendición, deziendo que pedía merced a Dios que.l diese e le otorgase la bendición que él le dava, ca él le dava todas bendiciones que.l podié dar (...) E así vuestro padre heredó complidamente la bendición del rey don Ferrando su padre e nuestro abuelo e porque la heredó e la ovo, púdola dar a vós. (2007, pp. 995-997)

Como he intentado demostrar, la Crónica abreviada no es una obra que se alinea con los modelos de la historiografía alfonsí, ni con la visión cortesana construida por el Rey Sabio. Es todo lo contrario, una primera reacción a esta herencia, en un periodo de la historia castellana donde tal pasado comienza a agrietarse, dando paso a nuevos modelos sociales en los que la nobleza ocupa un rol protagónico. Desde el punto de vista de la obra de Juan Manuel, se trata también de la primera articulación de una poética literaria y política, que desembocará inevitablemente en un desafío abierto a la legitimidad dinástica que Alfonso X intentó establecer en sus dos estorias.

\section{REFERENCIAS}

\section{Fuentes documentales}

Crónica de Alfonso XI (H). Biblioteca Nacional de España, ms. 10132, fols. 165r-389v. 
Crónica manuelina (Br). British Library, ms. Egerton 289.

Estoria de España (E1). Real Biblioteca del Monasterio de El Escorial, ms. Y-I-2.

Estoria de España (E2). Real Biblioteca del Monasterio de El Escorial, ms. X-I-4.

Estoria de España (Q). Biblioteca Nacional de España, ms. 5795.

Estoria de España (T). Biblioteca Menéndez Pelayo, ms. M-550.

\section{BiBliografíA}

Alfonso X. (2009). General estoria (P. Sánchez-Prieto Borja, Ed., Vols. 1-10). Madrid: Fundación José Antonio de Castro.

Alfonso X. (2014). Lapidario. Libro de las formas e imágenes que son en los cielos (P. Sánchez-Prieto Borja, Ed.). Madrid: Fundación José Antonio de Castro.

Ayerbe-Chaux, R. (1989). The Intellectual and Spiritual Relation of Don Juan Manuel to the Dominicans. En E. B. King, J. T. Shaefer \& W. B. Wadley (Eds.), Monks, Nuns, and Friars in Mediaeval Society (pp. 153-160). Sewanee: The Press of the University of the South

Bajtín, M. M. (2019). La novela como género literario (C. Ginés Orta, Trad.). Zaragoza: Prensas de la Universidad de Zaragoza.

Bautista, F. (2014). Autoría, niveles literarios y autocita. El Libro de los estados en la obra de don Juan Manuel. Voz $y$ letra, 25(1-2), 7-15.

Bautista Crespo, J. (2000). La Estoria de España y las crónicas generales. En I. Fernández-Ordóñez (Ed.). Alfonso X el Sabio y las crónicas de España (pp. 107-132). Valladolid: Universidad de Valladolid.

Beauvais, V. de. (1964). Speculum quadruplex sive Speculum maius (Vol. 1-4). Graz: Akademische Druck.

Benítez Guerrero, C. (2018). Piezas liminares de la historiografía postalfonsí. Edición y análisis del prólogo de la Crónica de tres reyes. In F. J. Hernández, R. Sánchez Ameijeiras \& E. Falque (Eds.), Medieval Studies in Honour of Peter Linehan (pp. 345-371). Florencia: Edizioni del Galluzzo.

Benito-Vessels, C. (1994).Juan Manuel. Escritura y recreación de la historia. Madison: Hispanic Seminary of Medieval Studies.

Cabot Garrido, A. (2020). Concepción de la persona y vida humanas en la quinta parte de El conde Lucanor. En M. Bellmunt Serrano \& J. Mahiques Climent (Eds.), Literature, Science and Religion. Textual Transmission and Translation in Medieval and Early Modern Europe (pp. 63-82). Kassel: Reichenberger.

Catalán, D. (1962). De Alfonso X al conde de Barcelos. Cuatro estudios sobre el nacimiento de la historiografía romance en Castilla y Portugal. Madrid: Gredos.

Catalán, D. (1966). El Toledano romanzado y las Estorias del fecho de los godos del siglo XV. En Estudios dedicados a James Homer Herriott (pp. 9-102). Madison: University of Wisconsin.

Catalán, D. (1969). Poesía y novela en la historiografía castellana de los siglos XIII y XIV. En Melánges offerts à Rita Lejeune, professeur à l'Université de Liège (pp. 423-441). Gembloux: Jules Duculot.

Catalán, D. (1992). Don Juan Manuel ante el modelo alfonsí. El testimonio de la Crónica abreviada. En La Estoria de España de Alfonso X. Creación y evolución (pp. 197-229). Madrid: Castalia. (Reimpreso de Juan Manuel Studies, pp. 17-51, por I. Macpherson, Ed., 1977, Londres: Tamesis).

Catalán, D. y M. S. De Andrés (1970). La Crónica de 1344. Estudio histórico. En D. Catalán y M. S. De Andrés (Eds.), Edición crítica del texto español de la Crónica de 1344 que ordenó el Conde de Barcelos don Pedro Alfonso (pp. xiiixciv). Madrid: Gredos.

Cintra, L. F. L. (Ed.). (1951-1965). Crónica geral de Espanha de 1344 (Vols. 1-4). Lisboa: Academia Portuguesa da História. 
Cossío Olavide, M. (2019a). "Algunos moros muy sabidores”. Virtuous Muslim Kings in Examples 30 and 41 of $E l$ conde Lucanor. Bulletin of Spanish Studies, 97(2), 127-138. doi: https://doi.org/10.1080/14753820.2020.172 9619

Cossío Olavide, M. (2019b). "Non ha tan buena escuela cuemo casa de señores”. El consejero caballeresco en el Libro del cavallero et del escudero de don Juan Manuel. Lexis, 43(2), 517-559. doi: https://doi.org/10.18800/lexis.20 1902.007

Cossío Olavide, M. (2022a, en prensa). "La muerte que anda todo el día entre los pies”. Muerte regia y nobiliaria en la clerecía señorial de don Juan Manuel. En M. Cabrera, M. T. López de Guereño Sanz y F. Miranda (Eds.), Muerte y poder de principes en la Europa medieval. Madrid: Sílex.

Cossío Olavide, M. (2022b, en prensa). "Letradura, entendimiento y buen seso". El consejero regio en el Libro de los estados de Juan Manuel. Revista canadiense de estudios hispánicos.

Deyermond, A. (1984). Introducción. En R. Ayerbe-Chaux (Ed.), Libro del conde Lucanor (pp. 3-49). Madrid: Alhambra.

Dyer, N. (1990). Alfonsine Historiography. The Literary Narrative. En R. I. Burns (Ed.), Emperor of Culture. Alfonso X the Learned of Castile and his Thirteenth-Century Renaissance (pp. 141-158). Filadelfia: University of Pennsylvania Press.

Fernández Fernández, L. (2013). Arte y ciencia en el scriptorium de Alfonso Xel Sabio. Sevilla: Universidad de Sevilla.

Fernández-Ordóñez, I. (1992). La abbreviatio en nuestra literatura medieval. Reflexiones a la luz de la labor historiográfica alfonsí. En M. Ariza, R. Cano, J. Mendoza y A. Narbona (Eds.), Actas del II Congreso Internacional de Historia de la Lengua Española (Vol. 2, pp. 631-640). Madrid: Pabellón de España.

Fernández-Ordóñez, I. (2000a). El taller de las Estorias. En I. Fernández-Ordóñez (Ed.). Alfonso X el Sabio y las crónicas de España (pp. 61- 82). Valladolid: Universidad de Valladolid.

Fernández-Ordóñez, I. (2000b). La transmisión textual de la Estoria de España y de las principales crónicas de ella derivadas. En I. Fernández-Ordóñez (Ed.), Alfonso X el Sabio y las crónicas de España (pp. 219-260). Valladolid: Universidad de Valladolid.

Fernández-Ordóñez, I. (2000c). Variación en el modelo historiográfico alfonsí en el siglo XIII. Las versiones de la Estoria de España. En G. Martin (Ed.), La historia alfonsi. El modelo y sus destinos (siglos XIII-XV) (pp. 41-74). Madrid: Casa de Velázquez.

Fernández-Ordoñez, I. (2018). Actores y autores en la historiografía regia de la Baja Edad Media ibérica. 1200-1450. En J.-P. Jardin, P. Rochwerth-Zuili y H. Thieulin-Pardo (Eds.), Histoire, femmes, pouvoirs. Peninsule Ibérique (IX $-X V^{e}$ siècle). Mélange offerts au Professeur Georges Martin (pp. 201-222). París: Clasiques Garnier.

Ferreira, M. do R. (2012). 'Amor e amizade antre os nobres fidalgos da Espanha'. Apontamentos sobre o prólogo do Livro de Linhagens do Conde D. Pedro. Cahiers d'études hispaniques médiévales, 35, 93-122. doi: https://doi.o $\mathrm{rg} / 10.3406 / \mathrm{cehm} .2012 .2276$

Funes, L. (1997). El modelo historiográfico alfonsi. Una caracterización. Londres: Queen Mary and Westfield College.

Funes, L. (2000). Don Juan Manuel y la herencia alfonsí. En M. Freixas, S. Iriso y L. Fernández Fernández (Ed.), Actas del VIII Congreso Internacional de la Asociación Hispánica de Literatura Medieval (Vol. 1, pp. 781-788). Santander: Asociación Hispánica de Literatura Medieval.

Funes, L. (2003). De Alfonso el Sabio al Canciller Ayala. Variaciones del relato histórico. Conclusiones del seminario dictado en la Universidad de Buenos Aires, agosto-noviembre de 2002. Memorabilia, 7. Recuperado de http:// www.parnaseo.uv.es/Memorabilia/Memorabilia7/Funes/Funes.htm

Funes, L. (2008). Elementos para una poética del relato histórico. En A. Arizaleta (Ed.), Poétique de la chronique. L'écriture des textes historiographiques au Moyen Âge, Péninsule Ibérique et France (pp. 241-274). Toulouse: Université de Toulouse Le Mirail. doi: 10.4000/books.pumi.38923

Funes, L. (2014). Historiografía nobiliaria castellana del periodo post-alfonsí. Un objeto en debate. La Corónica, 43(1), 5-38. doi: https://doi.org/10.1353/cor.2014.0040 
Funes, L. (2015). Estorias nobiliarias del período 1272-1312. Fundación ficcional de una verdad histórica. En M. Haro Cortés (Ed.), Literatura y ficción. Estorias, aventuras y poesia en la Edad Media: Vol. 1 (pp. 165-175). Valencia: Universitat de València.

Funes, L. (2016). La leyenda de la blasfemia del Rey Sabio. Revisión de su itinerario narrativo. eSpania, 25. doi: http s://doi.org/10.4000/e-spania.25873

Funes, L. (2019). Crónicas medievales en los umbrales de la modernidad. El caso de la Crónica particular de San Fernando. En I. Tomassetti (Ed.), Avatares y perspectivas del medievalismo ibérico (Vol. 1, pp. 207-217). San Millán de la Cogolla: Cilengua.

Funes, L. y Qués, M. E. (1995). La historia disidente. El lugar del Libro de las armas en el discurso historiográfico del siglo XIV castellano. Atalaya, 6, 71-78

Gingras, G. (1990). The Medieval Castilian Historiographical Tradition. From Alfonso X to López de Ayala. Romance Languages Annual, 2, 419-425.

Gomes, R. B. (2006). O Dom do Rei. Dádiva e vocabulário feudo-vassálico nos relatos cronisticos do reinado de D. Dinis. [Tesis de maestría, Universidade de Porto].

Gómez Redondo, F. (1998-2007). Historia de la prosa medieval castellana (Vols. 1-4). Madrid: Cátedra.

Gómez Redondo, F. (2000). La construcción del modelo de crónica real. En I. Fernández-Ordóñez (Ed.), Alfonso Xel Sabio y las crónicas de España (pp. 133-158). Valladolid: Universidad de Valladolid.

Guenée, B. (1985). L'historien et la compilation au XIII ${ }^{\mathrm{e}}$ siècle. Journal des savants, 119-135. doi: https://doi.org/1 $0.3406 /$ jds.1985.1487

Hathaway, N. (1989). Compilatio. From Plagiarism to Compiling. Viator, 20, 19-44. doi: https://doi.org/10.1484/j .viator.2.301346

Hijano Villegas, M. (2006). Continuaciones del Toledano. El caso de la Historia hasta 1288 dialogada. En F. Rico (Ed.). El relato historiográfico. Textos y tradiciones en la España medieval (pp. 123-148). Londres: Queen Mary and Westfield College.

Hijano Villegas, M. (2011). Fuentes romances de las crónicas generales. El testimonio de la Historia menos atajante. Hispanic Research Journal, 12(2), 118-134. doi: https://doi.org/10.1179/174582011X12943155134229

Hijano Villegas, M. (2014). Historia y poder simbólico en la obra de don Juan Manuel. Voz y letra, 25(1-2), 71-109.

Hijano Villegas, M. (2016). El manuscrito Egerton 289 de la British Library y la Crónica manuelina.e-Spania, 25. doi: https://doi.org/10.4000/e-spania.26096

Juan Manuel (1991). Libro de los estados (I. R. Macpherson y R. B. Tate, Eds.). Madrid: Castalia.

Juan Manuel (2007). Crónica abreviada. En C. Alvar y S. Finci (Eds.), Obras completas (pp. 7-297). Madrid: Fundación José Antonio de Castro.

Juan Manuel (2011). Libro de la caza. En J. M. Fradejas Rueda (Ed.), Don Juan Manuel y el Libro de la caza (pp. 127-208). Tordesillas: Seminario de Filología Medieval.

Kinkade, R. P. (Ed.). (1968). Los Lucidarios españoles. Madrid: Gredos.

Lucano (2009). De bello civili libri X (D. R. Shackleton Bailey, Ed.). Berlín: Walter de Gruyter.

Lucía Megías, J. M. (1995). Edición crítica del Libro del caballero Zifar [Tesis doctoral, Universidad de Alcalá de Henares].

Macpherson, I. (Ed.). (1980). Juan Manuel. A Selection. Londres: Tamesis.

Martin, G. (1994). Alphonse X maudit son fils. Atalaya, 5, 151-179.

Mencé-Caster, C. (2011). Un roi en quête d'auteurité. Alphonse $X$ et l'Histoire d'Espagne (Castille, XIII siècle). Lamentin: Caraïbéditions. doi: https://doi.org/10.4000/books.esb.260

Menéndez Pidal, R. (1955). Tradicionalidad de las crónicas generales de España. A propósito de los trabajos de L. F. Lindley Cintra. Boletín de la Real Academia de la Historia, 136(2), 131-197.

Montoya Martínez, J. (2002). Del scriptorium fernandino al de Alfonso X. La corte literaria de Fernando III. Alcanate, 3, $165-190$. 
Morrison, F. A. (1935). The Treatment of Fernán González in the Crónica abreviada as Compared with the Primera crónica general [Tesis de maestría, University of Minnesota].

Orduna, G. (2011). Los prólogos a la Crónica abreviada y al Libro de la caza. La tradición alfonsí y la primera época en la obra literaria de don Juan Manuel. En J. M. Fradejas Rueda (Ed.). Don Juan Manuel y el Libro de la caza (pp. 105-119). Tordesillas: Seminario de Filología Medieval. (Reimpreso de 1979, Cuadernos de historia de España, 51-52, pp. 123-144).

Pattison, D. (1992). British Library MS Egerton 289. A Glipse of the Crónica manuelina. La Corónica, 21(1), 15-30

Pichel, R. y Rodríguez Porto, R. M. (2020). La tradición manuscrita de la Estoria de Espanna en el siglo XIV. Notas codicológicas sobre los testimonios $Q$ (BNE 5795) y T (BMP 550). Bulletin of Hispanic Studies, 97(5), 527-554. doi: https://doi.org/10.3828/bhs.2020.30.

Rodríguez Porto, R. M. (2009). Horizonte literario y artístico de la corte castellana ca. 1350. Apuntes sobre la Crónica troyana de Alfonso XI (Escorial, H.I.6). En R. Alcoy i Pedrós (Ed.), El Trecento en obres. Art de Catalunya $i$ d'Europa al segle xiv (pp. 405-415). Barcelona: Universitat de Barcelona.

Saracino, P. E. (2006). La Crónica abreviada de don Juan Manuel. Una 'lectura desviada' de la crónica alfonsí. Medievalia, 38, 1-10.

Saracino, P. E. (2013). La rebeldía ante la figura de autoridad en el relato fundacional del condado de Castilla. Olivar. Revista de literatura y cultura españolas, 14(19), 1-24.

Saracino, P. E. (2014). Introducción. En P. E. Sararino (Ed.). Crónica de Sancho IV (pp. ix-cxcv). Buenos Aires: Incipit.

Savo, A. (2014). Porque fago libros. Authority and Authorship in the Works of Juan Manuel [Tesis doctoral, Yale University].

Shadis, M. (2009). Berenguela of Castile (1180-1246) and Political Women in the High Middle Ages. Nueva York: Palgrave

Sontag, S. (1966). Against Interpretation and Other Essays. Nueva York: Farrar, Straus \& Giroux.

Ward, A. (2012). El prólogo historiográfico medieval. Cabier d'études hispaniques médiévales, 35, 61-77. doi: https:/ /doi.org/10.3406/cehm.2012.2274

Ximénez de Rada, R. (1987). Historia de rebus Hispanie, sive Historia gothica (J. Fernández Valverde, Ed.). Turnhout: Brepols.

\section{Notas}

1 Este artículo es fruto de la colaboración con el proyecto de investigación "HERES. Patrimonio textual ibérico y novohispano. Recuperación y memoria" (CAM, 2018-T1/HUM-10230).

2 En el prólogo de la Crónica de tres reyes:

E por esto el muy alto e muy noble e mucho onrado e muy bien abenturado señor don Alfonso, por la gracia de Dios rey de Castilla (...) aviendo a boluntad que los fechos de los reyes que fueron ante que él fuesen fallados en escrito, mandó catar las corónicas e estorias antiguas e falló escrito por corónica en los libros de su cámara los fechos de todos los reyes que fueron en España, desde los primeros reyes godos fasta el rey don Rodrigo, e después desde el rey don Pelayo que fue el primero rey de León fasta el tiempo que finó el rey don Fernando (...) E porque acaecieron muchos fechos en los tiempos de los reyes que fueron después de aquel rey don Fernando los cuales non eran puestos en corónica, por ende este rey don Alfonso que es llamado el Conqueridor, entendió que aquellos fechos fincavan en olvido, e porque fuesen sabidas las cosas que acaecieron en los tiempos del rey don Alfonso su visabuelo el Sabio e en el tiempo del rey don Sancho el Bravo su abuelo e en tiempo del rey don Fernando su padre, mandolas escrivir en este libro, porque los que adelante vinieren sepan en cómo pasaron las cosas en tiempo de los reyes sobredichos. (Benítez Guerrero, 2018, pp. 364-365).

3 La Crónica de Alfonso XI relata que después de la Vega de Granada, Juan Manuel “sopo en cómo eran muertos estos dos infantes [don Joán e don Pedro], e luego tovo ojo por la tutoría toda, teniendo que non avía ý ninguno para ella sinon él" (fol. 178ra). El noble solucionó su aspiración de una forma creativa, aunque a todas vistas ilegal:

[E]n este tiempo estava en Cuéllar don Joán fijo del infante don Manuel e eran con él don Lope fijo de don Diego e algunos de los concejos de Estremadura. E fizo un sello de nuevo del rey e llamosse tutor del rey. E cuando lo sopieron los concejos e los 
perlados e los omnes buenos de la tierra estrañáronlo mucho teniendo que non podía fazer sello aviendo el rey su chancellería e sus sellos complidos. E por este sello començó a usar e a dar oficios e tierras e a librar pleitos. (fol. 179va)

En el Libro de los estados, Juan Manuel escribe líneas que corroboran la gravedad de su actuación:

El más onrado oficio e de mayor pro e que forçadamente á de saber lo más de la fazienda del señor e de las [sus] poridades es el chanceller, que el oficio del chanceller es que deve tener los sellos del señor e mandar fazer las cartas todas (...) Ca pues non puede ser carta sin ser sellada, non puede el señor cosa mandar fazer que el chanceller non lo sepa e a su mano e a su poder non aya de venir. (1991, p. 285)

4 El prólogo en tercera persona, como el del Libro de la caza, sugiere que la crónica fue escrita por uno o varios miembros de su taller señorial. Las primeras líneas parecen constatar la percepción de una autoría supervisada, estableciendo que no hay diferencia entre el auctor que escribe permanu propria y el que encarga libros para que sean escritos por otros, pero cuya voluntad guía la escritura (un “actor”, según Fernández-Ordóñez, 2018): “E por esta razón los que fazen o mandan fazer algunos libros, mayormente en romance que es señal que se fazen para los legos que non son muy letrados" (2007, p. 65). Tal situación no va en contra de los modelos medievales de autoría, como la ofrecida por los historiadores de la $G E$ (Alfonso X, 2009):

Del escrivir d'estas palabras avedes oído en el començamiento d'este capítulo cómo dixo Nuestro Señor que Él las escrivirié. E aquí dize en el (...) Éxodo que las mandó escrivir a Moisén, e avredes otrossí en el libro que á nombre Deuteronomio (...) que diz que Nuestro Señor que Él mismo las escrivió; e semeja que son contrallas estas razones. E sobr'esta contralla fabla maestre Pedro e depártela d'esta guisa: diz que todo es bien dicho e que podemos entender e dezir que compuso Nuestro Señor las razones de los mandados e que ovo Él autoridad e el nombre dend porque las mandó escrivir, mas que las escrivió Moisén, assí como dixiemos nós muchas vezes el rey faze un libro non por que.l él escriva con sus manos, mas porque compone las razones d'él e las emienda e yegua e endereça e muestra la manera de cómo se deven fazer, e desí escrívelas qui él manda, peró dezimos por esta razón que el rey faze el libro. Otrossí cuando dezimos que el rey faze un palacio o alguna obra non es dicho porque lo él fiziesse con sus manos mas porque.l mandó e dio las cosas que fueron mester pora ello; e qui esto cumple aquel á nombre que faze la obra, e nós assí veo que usamos de lo dezir. (Vol. 2, pp. 392-393)

Otra huella del taller juanmanuelino es la observación, también en el prólogo, sobre cómo funcionaban los talleres alfonsíes y cómo se relacionaban quienes ahí trabajaban con el rey:

Avía en su corte muchos maestros de las ciencias e de los saberes a los cuales él fazía mucho bien (...)[e] avía muy grant espacio para estudiar en las materias de que quería componer algunos libros, ca morava en algunos logares un año e dos e más e aun, segund dizen los que vivían a la su merced, que fablavan con él los que querían e cuando él quería e ansí avía espacio de estudiar en lo qu'él quería fazer para sí mismo e aun para veer e esterminar las cosas de los saberes qu'él mandava ordenar a los maestros e a los sabios que traía para esto en su corte" (2007, p. 67).

Llama mucho la atención que la fuente de esta información no sea la experiencia de Juan Manuel como lector de Alfonso X - como en el resto del prólogo y en el del Libro de la caza-, sino la de un letrado o un escriba ("los que vivían a la su merced"), alguien para quien pudo existir un paralelo bastante claro entre la labor que su señor le encomendó y la del Rey Sabio, cuya fama como investigador y patrón de las letras aún resonaba entre los letrados y los escribanos de principios del siglo XIV.

5 La $C M$ está dividida en tres libros, los dos primeros relacionados con la Versión primitiva, mientras que el último es una redacción postalfonsí. Para propósitos de comparación, las citas se hacen a los manuscritos más cercanos a cada sección. Sobre la historia del texto y su correspondencia con la EE, véanse Menéndez Pidal (1955), Catalán (1962, 1966 y 1977/1992), Pattison (1992), Fernández-Ordoñez (2000b) e Hijano Villegas (2014).

6 Aunque recientemente Pichel y Rodríguez Porto (2020) sostienen:

Se antoja difícil creer que don Juan no hubiese advertido el carácter híbrido de su fuente, dado que es precisamente en estos años cuando (...) controlaba la cancillería regia, teniendo acceso a los códices regios y, presumiblemente, también [a] los cuadernos de trabajo del taller historiográfico alfonsí. (p. 550)

Encuentro improbable que Juan Manuel tuviera acceso directo a la cámara regia durante los dos primeros años de la tutoría, pues la reina María, quien lo recelaba en extremo, fue su guarda hasta su muerte en 1321. Nada indica, por otro lado, que tuviera contacto con la $C M$ en la cámara regia y no por otros medios. No deben olvidarse el importante poder político que manejó en estos años y sus constantes desplazamientos, que le facilitarían acceder a las obras de Alfonso X dispersas por la Península. Sobre su capacidad para identificar el carácter híbrido del texto, lo creo poco posible en base al citado argumento de Funes. Esto habría requerido que Juan Manuel tuviera no solo un conocimiento profundo de 
la $E E$ alfonsí, sino de las redacciones posteriores, y que fuera capaz de identificar las particularidades que distinguían la copia que el poseyó de aquellas provenientes de otras ramas.

7 Para evitar un ejemplo tomado de Borges (Pierre Menard), recuérdese lo escrito por Bajtín (2019):

Cada palabra concreta (enunciado) encuentra ese objeto hacia el que se dirige, por así decirlo, ya mencionado, discutido, valorado, envuelto en un velo que lo oscurece, o, por el contrario, envuelto en la luz de las palabras ajenas que ya se han dicho sobre él. El objeto está enredado y penetrado por opiniones y puntos de vista generales, valoraciones y acentos ajenos. La palabra orientada hacia su propio objeto entra en este medio, dialógicamente agitado y tenso de palabras, valoraciones y acentos ajenos, se entrelaza con sus complejas relaciones recíprocas, se funde con algunas, repele otras, se entrecruza con unas terceras. (p. 512)

8 Aportan a este argumento los numerosos estudios de Malcolm Parkes, Mary y Richard Rouse, Bernard Guenée y Alastair Minnis, quienes a menudo citan la teoría de autoría que Buenaventura avanza en sus Commentaria al Libri sententiarum del Lombardo. Como indica Savo (2014), más cercano al propósito de Juan Manuel resulta el prólogo del Libellus apologeticus de Vicente de Beauvais (1964):

Porro ne quis in hoc opere vel de nouitate, vel de nimia prolixitate me aestimet argumendum, quoniam hoc ipsum opus novum quidem est simul et antiquum, breve quoque pariter et prolixum. Antiquum certe auctoritate et materia. Novum vero partium compilatione, et earum aggregatione. Breve quoque propter multorum dictorum in breve perstrictionem. Logum nihilominus propter immensam materiae multitudinem (...) Cum hoc ipsum opus utique meum simpliciter non sit, sed illorum potius ex quorum dictis fere totum illud contexui, nam ex meo ingenio pauca vel nulla addidi. Ipsorum igitur est auctoritate, nostrum autem sola ordinatione. (cols. 3-4)

9 Puede descartarse la aparente contradicción entre los campos retóricos de la amplificatio ("complidamente", "complido", "apuestas razones") y de la abbreviatio ("menos palabras"), que, sospecho, es una manifestación del torcido sentido del humor del autor, ya que la EE es cualquier cosa excepto breve. Quizá valga recordar el prólogo del Libro de la caza (2011), donde se describe el estilo alfonsí como de una prosa desarrollada y alargada, a la que sería difícil añadir algo: “e tan complidamente lo fizo que bien cuidan que non podría otro emendar nin enader ninguna cosa más de lo que él fizo” (p. 130).

10 Esta profecía ya figura en el prólogo del Toledano (1987): "Fidelis antiquitas et antiqua fidelitas primeuorum (...) inuestigantes experimenta rerum et enigmata figurarum futurorum noticie prouiderunt et duce spiritu presencia perceperunt et futura indagiis prenouerunt” (p. 5). Para Ximénez de Rada, sin embargo, los antiguos aprenden de los hechos inmateriales divinos (facta (...) Dei inuisibilia), a los que acceden con la ayuda de la revelación divina (diuina reuelatione). Este entendimiento solo es posible por la guía del espíritu de Dios. Esta visión ortodoxa, que desaparece en la versión alfonsí, es retomada en el prólogo de la Crónica abreviada.

[11] Sobre las deudas de Juan Manuel con Aristóteles y Tomás de Aquino, véanse Macpherson (1980), Deyermond (1984), Ayerbe-Chaux (1989) y Cabot Garrido (2020).

12 El prólogo sobrevive solamente en una refundición del siglo XV, conocida como Crónica geral de Espanha de 1344, y no en la redacción primitiva de la Crónica de 1344. Aunque su atribución es materia de discusión (Catalán y De Andrés, 1970), siguiendo a Gomes (2006) y Ferreira (2012) asumo que refleja en mayor o menor medida el espíritu del original compuesto por Pedro Afonso, como lo sugieren los numerosos paralelos temáticos entre esta versión y el prólogo del Livro de linhagens.

13 Un tercer caso de reformulación de la materia introductoria de la $E E$ se encuentra en la Crónica de tres reyes. El tono regalista de su prólogo se distingue claramente de las anteriores redacciones nobiliarias, recuperando la importancia de la lealtad de los antiguos:

Por muchas guisas e por muchas maneras los antigos que fueron en los tiempos pasados quisieron que las cosas que eran falladas que pasaron se pudiesen saber. E por nobleza de sí mismos, seyendo leales a los que eran por benir, fiziéronlas escrivir entendiendo que por esta guisa las podrían mejor saber los que viniesen después d'ellos e aquellos fechos fincarían guardados e durarían luengos tiempos. E así (...) conviene que los fechos de los reyes, que tienen lugar de Dios en la tierra, sean fallados en escrito, señaladamente de los reyes de Castilla e de León. (Benítez Guerrero, 2018, pp. 363-364).

14 Las tensiones ideológicas entre los prólogos de las tres crónicas (Abreviada, Geral y Tres reyes) invitan a estudiarlas comparativamente y revisitar la visión sobre su función en la historiografía postalfonsí, y, en general, el lugar de los prólogos en la historiografía castellana medieval. Ward (2012) escribe:

Se podría imaginar que el peso de esta tradición [= las crónicas de Lucas de Tuy, Ximénez de Rada y Alfonso X] había de tener una influencia muy profunda en la historiografía posterior. Pero resulta que no es así, porque con la parcial excepción de la Crónica abreviada de Juan Manuel, las obras historiográficas que utilizaron las cuatro crónicas aquí analizadas como fuente casi nunca se aprovecharon del "espacio de libertad" de expresión que es el prólogo. Es más: muchas obras (...) como es el caso de la Crónica de 1344 de Pedro Afonso, se limitan a reproducir con ligeros retoques los prólogos que encontraron 
en sus fuentes (...) El mismo fenómeno se da en las crónicas que forman parte de la continuación de la tradición, o línea, alfonsí: [en] las crónicas de Fernán Sánchez de Valladolid (...) no se aprovecha del espacio prologal para ofrecer una visión propia del mundo y de la historia. (pp. 75-76)

15 Hay tres formas de supresión. La primera es la eliminación declarada de eventos poco pertinentes para la narración: "En el LXVIII ${ }^{\circ}$ capítulo e en el LXIX non fallamos ninguna cosa que cumpla poner en este libro" (2007, p. 85). La segunda es la supresión declarada de eventos ocurridos fuera de la Península, que son juzgados como irrelevantes: "En el LXXX' capítulo e LXXXI e LXXXII e LXXXIII e LXXXIIII ${ }^{\circ}$ dize de muchos fechos grandes que fizo Pompeyo (...) pero non cuenta ninguna cosa d'ellas que acaeciese en España e non lo ponemos en este libro" (2007, pp. 86-87). En ambas formas se recicla una fórmula empleada en la $E E$ alfonsí para indicar años donde no suceden eventos hispánicos de interés: "non fallamos ninguna cosa que de contar sea que a la estoria pertenesca" ( $E 2$, fol. $5 \mathrm{rb}$ ). La tercera es la supresión declarada de material falsamente inexistente en el modelo: "En el CCXXIII capítulo non dize ninguna cosa, nin en el CCXXIIII"” (2007, p. 112). Solamente en los 408 capítulos del primer libro de la crónica ocurren 26 abreviaciones de este tipo.

16 Una de las razones por las que la caída de los godos es dejada sin explicar en la Crónica abreviada puede encontrarse en las duras críticas de los historiadores alfonsíes sobre la nobleza y su rol en el colapso del reino visigodo, acción que va en contra de los ideales del sistema monárquico de Alfonso X:

E por ende los que fueron en tiempo del rey Vitiza e del rey Rodrigo, que fue el postrimero rey de los godos, e de los otros reis que fueron ante d'ellos e de cuales algunos fueron alçados reis por aleve, algunos por traición de muerte de sus hermanos o de sus parientes, non guardando la verdad nin el derecho que devieran ý guardar por quexa de ganar el señorío mal e torticieramientre como non devién; por ende los otros omnes que fueron otrossí en sus tiempos d'ellos formáronse con ellos e semejáronles en los pecados e por esta razón avivose la ira de Dios sobr'ellos, e desamparoles la tierra que les mantoviera e guardara fasta allí, e tollió d'ellos la su gracia. (E1, fols. 193vb-194ra)

17 Otra representación negativa de Escipión ocurre en la GE (Alfonso X, 2009), cuando aparece como una visión infernal en el discurso del soldado resucitado por la adivina Ericto: "e vi al Cipión llorar al su linage malandante cómo avié a perecer en África en tierra de Libia, e es este Cipión el que fue el mayor enemigo de Cartago e que la judgó para destroír e la destruyó él" (Vol. 10, p. 210). Este pasaje amplifica notablemente la fuente de los historiadores alfonsíes, la Farsalia de Lucano (2009): “deplorat Libycis perituram Scipio terris / infaustam subolem; maior Carthaginis hostis” (vv. 788-789). El episodio de la reina tiene otras réplicas en la EE, aunque la más notoria ocurre en las Cantigas de Santa María. La cantiga 205, que corrige las acciones atribuidas al Emiliano, relata la salvación mariana de una mora y su hijo de una torre incendiada durante la conquista de un castillo.

18 Como es sabido, los historiadores alfonsíes a menudo deben armonizar visiones contradictorias de sus fuentes. Con Escipión sucede esto. Es descrito en capítulos anteriores en términos positivos y de nobleza: "E este Cipión era omne cuerdo e esforçado" ( $Q$, fol. 21ra), pues actúa defendiendo el señorío de Roma de las revueltas de los cartaginenses. Pero también tienen que lidiar con la brutalidad que le transmite la Historia adversus paganos de Paulo Orosio y con la destrucción por el fuego de Cartago, que evoca el destino de Troya, ciudad de gran importancia simbólica en el imaginario medieval castellano (Rodríguez Porto, 2009). Esta resolución se logra con la división del contenido en dos partes, mediadas por un salto analéptico a la fundación de la ciudad y la historia de Dido y Eneas. La crónica, por oposición, elimina todo el material que pueda tener una connotación negativa sobre este "buen omne" (2007, p. 85), y atribuye la responsabilidad de la caída de la ciudad ibérica a un sentimiento generalizado entre los romanos: "E porque los de Roma avién ende grant embidia, por esso ovieron guerra con ella fasta que la destruyeron” (2007, p. 85). $19 E E$ :

E dos ricos omnes que ý eran que avién nombre el uno Bruto e el otro Casio ovieron su fabla e su consejo con otros dozientos e sesenta cavalleros romanos que matasen a Julio César a traición. E eran ý todos venidos con seños estoques so los mantos, e tanto que se posó Julio César, fuéronlo todos ferir. ( $Q$, fol. $71 \mathrm{va})$

20 Los cronistas alfonsíes comparan el gobierno senatorial con las cortes castellanas: "E sabed que eran llamados corte los senadores e los cónsules" ( $Q$, fol. $87 \mathrm{vb})$.

$21 E E$ :

Levantose grant desabenencia en la cibdat de Roma entre la corte e los cavalleros e el pueblo. E (...) los senadores e los cónsules que veién la grant crueldat de los emperadores, los daños que contecieran al común por razón d'ellos e quisieran que non oviesse emperador d'allí adelante e que tornasse al primero estado en que solié seer ante que Julio César e que todo el governamiento fuesse en el alvedrío d'ellos. Mas los cavalleros e el pueblo, temiendo la cobdicia de los senadores e pagándose de los grandes dones que les davan los emperadores, alçaron por emperador a Claudio. ( $Q$, fol. $87 \mathrm{va}-\mathrm{b}$ )

22 En el Lucidario: 
Sepas que el pecado de Adam fueron tres parcioneros: el primero fue el diablo en figura de serpiente que lo andido e lo ordió, el segundo fue Eva que lo consejó, el tercero fue Adam que lo consentió e lo metió en obra (...) este pecado era fecho por tres. (Kinkade, 1968, p. 108)

23 Benito-Vessels (1994) fue la primera en notar la utilidad de esta omisión para establecer las diferencias ideológicas entre la EE y la Crónica abreviada.

24 El episodio del arcipreste también aparece en la primera parte del manuscrito que transmite la $C M$, una refundición narrativizada de la $E E$ del siglo XVI. El texto llega incompleto por el mal estado de los folios iniciales:

-Señor, algo se á de aventurar por salvar [...] vida. Apartaos que yo quiero hazer lo que el acipreste demanda. Y tomó al acipreste por la mano y él [...] la abraçar. La infanta travó d'él tan fuertemente [...] tuvo ý hasta que el conde llegó, y con un cuchillo que el [...] acipreste traía, lo mató. ( $\mathrm{Br}$, fol. 10r)

25 Leonardo Funes me advierte que él no ve en la figura de Berenguela un rasgo molinista, porque la fuente de estas palabras, el Toledano, ya incluye este elogio. Ciertamente Ximénez de Rada (1987) describe a Berenguela en términos igualmente positivos (ingeniosa e industriosa, pp. 281-282). Empero, no se puede negar el atractivo que este pasaje tuvo para los refundidores sanchíes. A diferencia de los notables alejamientos de De rebus Hispaniae de los equipos alfonsíes, la Versión retóricamente amplificada mantiene características de este texto que son valiosas para el pensamiento molinista: la participación de la reina en la administración del reino, su ingenio, su decoro y su comprensión de las formas del comportamiento humano. Siguiendo a Shadis (2009, pp. 158-59), creo que Berenguela prefigura el rol que María de Molina ocupa en otras obras realizadas por los letrados molinistas, como el Libro del cavalleroZifar o las crónicas que Fernán Sánchez de Valladolid escribe para Alfonso XI, especialmente la Crónica de Sancho IV y la Crónica de Fernando $I V$. En el prólogo del Zifar:

Doña María, que era reina de Castiella e de León (...) la cual fue muy buena dueña e de muy buena vida e de buen consejo e de buen seso natural e muy complida en todas buenas costumbres e amadora de justicia e con piedat, non argulleciendo con buena andança nin desesperando con mal andança cuando le acaecía, mas muy firme e estable en todos sus fechos, que entendié que con Dios e con razón e con derecho eran, así como se cuenta en el libro de la Estoria. (Lucía Megías, 1995, pp. 17-18)

26 Según Ximénez de Rada (1987): "Et comes Aluarus cepisset caligis ferreis calciari, percussus a Domino cepit grauissime infirmari” (p. 289). En la CM:

E así como cuenta el arçobispo el conde don Álvaro que era ý e andava vidiendo de todo esto, començóse a armar e armándose las brafoneras diz que le firió la mano de Dios de muy grant enfermedad, e pues que el conde don Álvaro fue enfermo. ( $B r$, fol. 195v)

27 Aureliano es uno de los emperadores de más feliz memoria en la $E E$ : "E segunt cuentan las estorias fue omne que semejó en sus fechos al grant Alexandre e a Julio César porque domó todas las tierras" ( $Q$, fol. 125ra-b). Como él, Probo "era por sus armas muy buen cavallero e muy loado" ( $Q$, fol. 126vb).

28 Sobre lo primero, se hace énfasis en las órdenes del Cid de tomar los arrabales de la ciudad para disminuir el suministro de alimentos de los sitiados: "mandó robar el Cid los arravales de Valencia por tal que se metiessen los moros dentro e encareciessen la vianda” (2007, p. 247). Esta es una estrategia de combate fronterizo que sería interesante para un defensor como Juan Manuel. Una vez tomada la ciudad, Rodrigo reúne a los pobladores y les promete "que les faría mucho bien e mucha merced. E mandóles que fuesen todos a sus heredades e que las labrasen e que él non querié d'ellos sinon el diezmo" (2007, p. 248).

29 Una errata del copista del manuscrito de la $C M$ es indicativo del tono amplificatorio de la Interpolación cidiana: "vi yo muchos, cuando vienen a él mandaderos de los omnes moros, que fincan desacordados" ( $\mathrm{Br}$, fol. 125r).

30 El manuscrito que transmite la $C M$ ofrece una versión amplificada que es muy valiosa para comprender las adiciones nobiliarias que este episodio sufre hasta el siglo XIV, demostrando la preocupación de los nobles por mantener sus derechos y sus fueros:

"E [rogó] por todos los ricos omes de sus reinos que les fiziese bien y merced e los toviese en justicia e razón sin vandería. E a los cavalleros fijosdalgo mandó e rogó que les guardase bien sus fueros e sus franquezas e sus libertades, non menguándoles ende cosa alguna, e los honrase mucho faziéndoles siempre bien e merced, pues le avían sido tan buenos e tan leales en todas las conquistas que él e sus antepasados avién avido contra moros enemigos de la fe. E así mesmo le rogó por todos los pueblos que les guardase sus fueros e libertades (...) e todo esto le fizo jurar e prometer por su boca que lo cumpliese. E le dixo más el santo rey, que si así lo que le avía rogado e mandado fiziese e cumpliese que la bendición de Dios e la suya oviese, e que faziéndolo al contrario que la maldición de Dios e la suya le alcançase e oviese. E el dicho don Alfonso respondió "Amén” e así lo otorgó. (fols. $237 \mathrm{r}-237 \mathrm{v}$ ) 
31 Creo que ambos pasajes son manifestaciones tempranas de la leyenda de la blasfemia de Alfonso X: la crítica que dirige a Dios por las menguas de la creación, que con su consejo podrían haberse evitado (véase Funes, 2016). Años después, Juan Manuel vuelve a recurrir a esta leyenda en el Libro de las tres razones, donde cuenta que la reina Beatriz de Suabia tuvo una pesadilla premonitoria durante su embarazo de Alfonso X. 